\title{
Real Options and Risk Dynamics
}

\author{
DIRK HACKBARTH \\ Boston University School of Management \\ and \\ TIMOTHY JOHNSON \\ University of Illinois, Urbana-Champaign
}

First version received September 2012; final version accepted April 2015 (Eds.)

\begin{abstract}
We examine the asset pricing implications of a neoclassical model of repeated investment and disinvestment. Prior research has emphasized a negative relation between productivity and equity risk that results from operating leverage when capital adjustment is costly. In general, however, expansion and contraction options affect risk in the opposite direction: they lower equity risk as profitability declines. The general prediction is a non-monotonic overlay of opposing real option and operating leverage effects. For parameters chosen to match empirical firm characteristics, the predicted non-monotonicities are quantitatively important, and are detectable in the data. The calibrated model implies that real option effects dominate operating leverage effects, and the average firm is best described by an increasing risk profile, a conclusion supported by conditional beta estimates. The baseline calibration helps explain the profitability premium in the cross-section, but makes the value puzzle worse. Panels with heterogeneous firms can deliver simultaneous profitability and value effects that match empirical levels.
\end{abstract}

Key words: Real options, Adjustment costs, Risk premia

JEL Codes: D31, D92, G12, G31

\section{INTRODUCTION}

An important recent goal of research in financial economics has been to understand how firms' equity risk and expected return behave in response to changes in their operating environment. In particular, the primary objective of the so-called investment-based asset pricing has been to link firms' productivity and investment opportunities to many of the well-documented puzzling associations between observable firm characteristics and stock returns in the cross-section, the premise being that there can be significant variation in a firm's real exposure to systematic risk as operating conditions change, and that investors' required compensation (the expected stock return or cost of equity capital) reflect these fluctuations.

This article examines this effort in the context of a general theory of firm dynamics. Rather than constructing a model to deliver a known fact (or set of facts) about stock returns, the design of our study is the other way around. From the model we deduce the implications for risk and expected return, and present affirmative evidence of new effects in the data. We then return to known anomalies and delineate the successes and shortcomings of this class of models. 

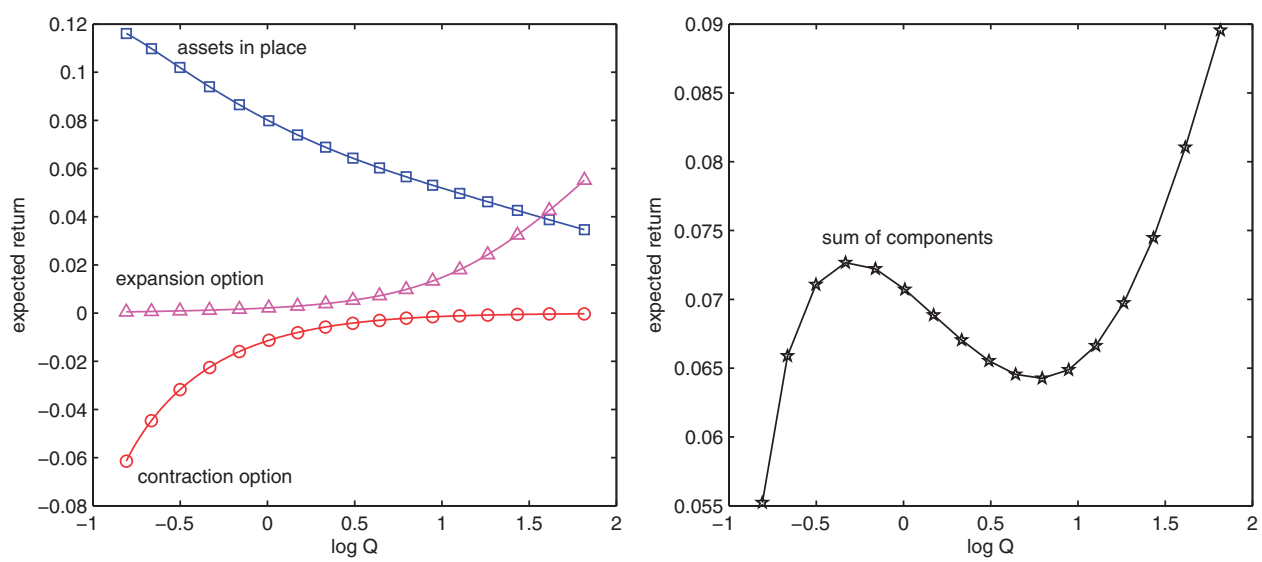

FIGURE 1

Components of risk premium

Notes: The left panel shows the three components of expected return plotted against the log of the market-to-book $(Q)$ ratio for a typical firm. The term due to assets-in-place is plotted as squares. The terms due to the contraction option and expansion option are plotted as circles and triangles, respectively. The right panel shows the sum of the three components.

We employ a neoclassical model of a firm with repeated investment and disinvestment options that experiences stochastic long-lived shocks to productivity. The building blocks of the model — real options, quasi-fixed operating costs, fixed and variable capital adjustment costs—are standard in the corporate investment literature. However, the asset pricing implications have not been elucidated. The model is transparent and tractable enough to serve as a standard reference for understanding how firm characteristics affect risk and expected return 1

The primary within-firm implication is that risk and expected return are sine-like functions of productivity 2 On the one hand, quasi-fixed costs create operating leverage, which lowers risk with profitability. On the other hand, as profitability rises, the firm's risk rises due to more valuable expansion options, and, as profitability declines, the firm's risk declines due to more valuable contraction options 3 As a result of these conflicting effects, the sum of the three components typically exhibits a concave region followed by convex region. Examples of the three components and their sum are plotted in Figure 1

The relative prominence of the three effects can vary substantially depending on firm characteristics, and the slope of expected return in the mid-section of the profitability range may have either sign. But the slope is nearly always increasingly positive near the end points. Because the concave/convex risk profile follows from a basic combination of operating leverage and real option effects, it applies very broadly to firms with a wide range of parameters. From this observation, we deduce a novel time-series effect. Since the autocorrelation of returns is

1. The solution is in closed form up to six constants that are pinned down by a simple system of algebraic equations. See Appendix A.

2. The model has a single-state variable that can be equivalently described by productivity, profitability, or Tobin's $Q$ (the market-to-book value ratio).

3. The option to expand increases risk because it confers the right to take on further productivity risk, in exchange for (riskless) cash. Similar to a call option on a stock, the expansion options' sensitivity to productivity shocks increases as the likelihood of exercise increases. Likewise, the contraction option has the properties of a put option, namely the right to dispose of risky assets (and receive riskless cash). The put has negative exposure to productivity shocks, which becomes more negative as the likelihood of exercise increases. 
dictated by the slope of the expected return graph, the model implies that that autocorrelation itself should have a consistent conditional dependence, first declining and then rising as a function of profitability.

We sharpen the model's predictions, quantitatively, under a particular parameterization chosen to match an array of operating and financial statistics computed from a large sample of U.S. companies. This baseline calibration features firms with moderate operating leverage and very valuable real options. In simulations of this calibration we confirm that a conditional specification of autocorrelation should exhibit the convex pattern deduced above. In addition, fitted measures of risk-as captured by market beta-exhibit the predicted concave/convex conditional pattern under the baseline parameters. When we take these predictions to our data, we do, in fact, find the analogous patterns. The importance of this evidence is not that the patterns themselves constitute predominant features of stock returns, but that their prediction from an a priori theory lends support to the view that a firm's operating environment strongly affects its risk and expected return.

Our results contain some surprises from the perspective of prior research. A notable theme of investment-based asset pricing has been to stress the increase in equity risk that can arise in response to deteriorating firm conditions 4 When firms have significant fixed costs and lack the ability to scale down in the face of negative productivity shocks, stockholders are stuck with increasing operating leverage in bad times. As a result, under these conditions, expected returns rise and valuations decline (e.g. as measured by $Q$ ). This logic has been applied to explain a variety of anomalies in which stock returns vary negatively with characteristics associated with positive firm developments. The most well known of these is the "value effect": expected returns decline as $Q$ rises in the cross-section. Similarly, returns decline among firms with high investment rates and high asset growth. Yet, our work suggests that the key firm characteristic required for these effects to be predicted by the model (i.e. a lack of real options) is unlikely to be relevant for an average firm in our sample.

In particular, we show that under even mild degrees of investment flexibility, the average return-profitability relation is actually increasing. In our baseline calibration, firms spend most of their time in the region dominated by expansion option effects. In addition, the data are best described by parameters with enough reversibility that operating leverage effects are muted. By contrast, parameter sets without important real option effects are inconsistent with the average characteristics of operating and return data. Effective irreversibility is also inconsistent with the conditional beta and autocorrelation functions that we find in the data.

This conclusion is not surprising from the perspective of the empirical literature on investment that directly documents substantial reallocation of physical capital and thus (from the point of view of asset sellers) reversibility of investment. For example, Eisfeldt and Rampini 2006) report that capital reallocation comprises $24 \%$ of investment in aggregate. Direct estimates of the average liquidation value of capital in Ramey and Shapiro 2001) and Bloom 2009) are closer to unity than to zero as a fraction of installed value.

The lack of support for irreversibility is not entirely bad news for investment-based asset pricing. Indeed, a second class of return patterns, in seeming contradiction to the ones just cited, suggests returns may rise in response to positive developments. The "momentum effect" is the positive association in the cross-section between lagged medium-term returns and future returns. The phenomenon of "post-event drift" is the tendency in long-horizon event studies of returns to continue in the same direction as the instantaneous reaction to significant firm-specific news, e.g. months or even quarters of abnormal outperformance following unexpectedly good earnings.

4. See e.g. Carlson et al, 2004, Zhang 2005, Cooper 2006, Li et al, 2009, and Ozdagli 2012. 
Finally, measures of profitability are positively associated with returns in the cross-section (see Fama and French 2006) and Novy-Marx 2013)).

While our model holds out the possibility that some or all of these phenomena may be due to real option effects, when we run the standard empirical tests in simulated return panels from the benchmark case, the corresponding implied coefficients are not large enough. Plausible variants of the baseline case can deliver an unconditional profitability effect of the same magnitude as found in the data. But, by necessity the basic model makes the value puzzle worse. Since profitability and book-to-market are monotonically related in the model, it implies a negative unconditional relation between book-to-market and returns.

The lesson we take from the model's failures here is the limitation of viewing the cross-section as consisting of ex ante identical firms. Other research has invoked additional state variables to attempt to resolve the paradox of profitability and valuation having opposite effects. But the literature has largely maintained the assumption of homogenous firm technology. The tractability of our model, however, offers the ability to readily solve for optimal firm policies and value functions in panels with many different firm types. We offer two examples that each merely exploit a single degree of variation.

First, we show that panels containing firms with different degrees of systematic risk, or cyclicality, can produce positive momentum, profitability, and value effects. While the univariate effects are modest, in multivariate tests the profitability and value effects are as large as in the data. Secondly, we show that panels containing small, fast-growing firms can deliver simultaneous positive profitability effects and negative investment effects. In both cases, we verify that the ability of firm characteristics to explain return variation is not subsumed by inclusion of estimated market betas as additional risk proxies.

To summarize, the contribution of the article is to analyse risk and expected return in a general setting that encompasses operating leverage and real option effects. The interplay of these effects, and in particular, their opposing forces in response to profitability shocks have not been previously emphasized by the investment-based asset pricing literature. Rather than constructing a model to reproduce particular return patterns, we ask the model to "talk back to us". It implies some novel conditional non-monotonicities in risk and expected return, for which we find supportive evidence in the data. Calibrated versions of the model cannot, however, go very far towards explaining the most well-known return anomalies. To this end, we point towards a promising direction for future research, namely, incorporating parameter heterogeneity into our depiction of the cross-section.

The outline of the article is as follows. The next section introduces the model and derives the main theoretical implications. Section 3 identifies the baseline parameters from the calibration exercise. It then assesses the quantitative implications of this case, performing parallel tests in real data and model-simulated data. Section 4 assesses the model's unconditional implications for the cross-section to shed light on the coexistence of value, momentum, and profitability effects. A final section summarizes our contribution and concludes.

\section{THE MODEL}

We employ a neoclassical investment model of a firm that experiences shocks to its profitability, while facing costs to both upward and downward adjustments of its scale. A number of related models have been used in the literature (see below). As described in the introduction, we believe that the tractability and transparency of this model make it a valuable contribution for studying how real options affect expected returns.

The setting is a continuous-time economy in which each firm is a claim to a real production function characterized by decreasing returns to scale and quasi-fixed operating costs. The firm 
has physical asset5 5 whose book value is denoted $K$. Output-or revenues net of variable costsare determined by $K$ together with the level of productivity $\theta$. The firm's profit flow (per unit time) is

$$
\Pi_{t}=\theta_{t}^{1-\gamma} K_{t}^{\gamma}-m K_{t}
$$

where $\gamma \in(0,1)$ captures returns to scale and $m>0$ denotes operating cost per unit of $K$. Unless adjusted by the firm, $K$ follows $d K / K=-\delta d t$, with depreciation rate $\delta \geq 0$.

The productivity process is assumed to evolve as a jump-diffusion according to the stochastic differential equation

$$
\frac{d \theta}{\theta}=\mu d t+\sigma d W^{\theta}-d N
$$

where $W$ is a standard Wiener process that generates unpredictable shocks and $N$ is a Poisson process with intensity $\eta$ that extinguishes the project at an exponentially distributed random time. The latter term is included to ensure that firms have finite life 6 Note that, for tractability, we consider only permanent productivity shocks.

To price claims to the firm, we assume the economy is characterized by a unique process for the intertemporal marginal rate of substitution (the pricing kernel or stochastic discount factor) denoted $\Lambda_{t}$ whose law of motion is given by

$$
\frac{d \Lambda}{\Lambda}=-r d t+\sigma_{\Lambda} d W^{\Lambda}
$$

Here $r$ is the riskless interest rate in the economy, $\sigma_{\Lambda}$ is the instantaneous volatility of marginal utility 7 The model is partial equilibrium because the discount factor process is taken to be exogenous. Again for tractability, we do not consider variations in business conditions: all the moments of the discount factor are assumed constant.

By definition of the stochastic discount factor, claims to future cash-flows are priced in the economy as the expectation of their product with the process $\Lambda$. To compute such expectations, we need to specify the covariance of the $d \theta$ process with $d \Lambda$. We assume the Brownian motion terms have correlation denoted $\rho$. In the empirically relevant case, investors are averse to $\theta$ risk, meaning $\rho<0$. In the general case (considered in the Appendix), the jump term may also be correlated with potential systematic jumps, which simply adds a constant to the firm's risk premium. For parsimony, the development here will assume the jump risk to be purely non-systematic.

When considering properties of collections of firms, we will need to make explicit assumptions on common factors. Clearly, common correlation across firms with the stochastic discount factor induces cross firm correlation. However, there may be additional sources of common variation. Our notation so far has suppressed firm-specific superscripts, which we will continue to do except where necessary. In general, all of the production function and stochastic process parameters may vary across firms. The specific assumption about the $i$-th firm's productivity shocks $d W^{\theta}=d W^{(\theta, i)}$ is that it is composed of three components: purely idiosyncratic variation, common variation due to correlation with $\Lambda$, and at most one other source of common unpriced variation. This may be implemented with a single additional parameter, as follows:

$$
d W^{(\theta, i)}=\rho^{(i)} d W^{\Lambda}+\rho^{(m, i)} d W^{m}+\sqrt{1-\left(\rho^{(i)}\right)^{2}-\left(\rho^{(m, i)}\right)^{2}} d W^{(I, i)}
$$

5. The economic logic of the model is not confined to physical capital. More generally, one could view $K$ as a bundle of productive factors that the firm has in place, encompassing anything that generates quasi-fixed operating costs and that is costly to adjust.

6. Terminal jumps are also employed in the models of Gomes et al. 2003) and Carlson et al. 2004, for example.

7. The Appendix generalizes the $\Lambda$ process to includethe possibility of a systematic jump event. 
where $d W^{\Lambda}, d W^{m}$, and $d W^{(I, i)}$ are mutually independent standard Wiener processes, and, for all $i, j, d W^{(I, i)}$ and $d W^{(I, j)}$ are also independent. Likewise, the idiosyncratic jump terms $d N^{i}$ and $d N^{j}$ are pairwise independent. Note that, while the stochastic discount factor in the economy is unique, firms may have different risk-reward characteristics depending on their correlation parameter $\rho^{(i)}$, which we will explore in Section 4

For present purposes, we study an all equity-financed firm. Recently, Ozdagli 2012) has analysed a version of the model studied here for a firm with debt. In a setting in which it is costly for the firm to deviate from a constant book leverage, interest expenses act to magnify the quasi-fixed operating costs. In Appendix B, we verify that the primary features we describe here for firm expected returns are preserved for equity expected returns under some reasonable formulations of debt determination.

We assume firms face both quasi-fixed and variable costs for either upward or downward adjustments to $K$. When increasing the scale of operations, the firm faces costs that are proportional to net revenue at the time of the adjustment, $F_{L} \theta^{1-\gamma} K^{\gamma}$, where $F_{L} \geq 0$ (the subscript will be explained below). In addition, the cost to investors of increasing $K$ by $\Delta K$ may exceed $\Delta K, e . g$. due to installation frictions. These costs are assumed linear: the amount required from investors is $P_{L} \Delta K$ where $P_{L} \geq 1$ can be regarded as a purchase price (per unit of capital). The deadweight loss from the adjustment is thus $\left(P_{L}-1\right) \Delta K$.

The form of the frictions for disinvestment are the same as those for investment. Specifically, for any contraction of scale there are fixed costs denoted by $F_{U} \theta^{1-\gamma} K^{\gamma}$. And the cash returned to investors when $K$ is lowered by $\Delta K$ is taken to be $P_{U} \Delta K$, where $P_{U} \leq 1$ can be regarded as a resale price (per unit of capital). In principle, we could even have $P_{U}<0$ due, e.g. to penalties for breaking contracts or clean-up costs. If the productivity process is extinguished, we assume the capital stock is valueless 8

Note that our assumptions here do not actually nest the case of pure irreversibility, in which the firm's only contraction option is to dispose of all capital at price zero. Even if we set $P_{U}=0$, our firm has the ability to scale down incrementally, which will typically dominate complete abandonment 9 Nevertheless, our solutions closely resemble those of the irreversible case when $P_{U}$ is low.

To our knowledge, the ability to repeatedly expand and contract under this cost structure has not previously appeared in the literature. Early contributions to the real options literature study an (upper) adjustment barrier. For example, Pindyck 1988) and Bertola 1998) model incremental investment and capacity choice under irreversibility. This literature typically does not consider disinvestment and investment jointly. Two exceptions are the two-period framework of Abel et al. 1996) and the continuous-time model of Abel and Eberly 1996), which is closer to ours, because they recognize that variation in investment and disinvestment costs implies important differences in investment dynamics. However, these papers do not study risk or expected return. More generally, disinvestment options have received little attention in the investmentbased asset pricing literature.

The firm's objective is to choose an investment/disinvestment policy, $K$, to maximize its market value:

$$
J(\theta, K)=\max _{K_{u}, u \geq t} \mathrm{E}_{t}\left\{\int_{t}^{\infty} \Pi\left(\theta_{u}, K_{u}\right) \Lambda_{u} / \Lambda_{t} d u\right\} .
$$

8. The modification in which capital is liquidated for $P_{0}>0$ when $\theta$ jumps to zero is straightforward and does not change any of the qualitative features of the model.

9. If $P_{U}<0$ or the fixed cost $F_{U}$ is large, our set-up may lead to negative firm value, which does not happen if abandonment is possible. In keeping with limited liability, therefore, if the solution to our original problem entails negative firm value, we re-solve the problem imposing the boundary conditions for abandonment $\left(V(U)=0, V^{\prime}(U)=0\right)$ instead of the ones derived in Appendix (A.6 and A.9) for the original problem. 


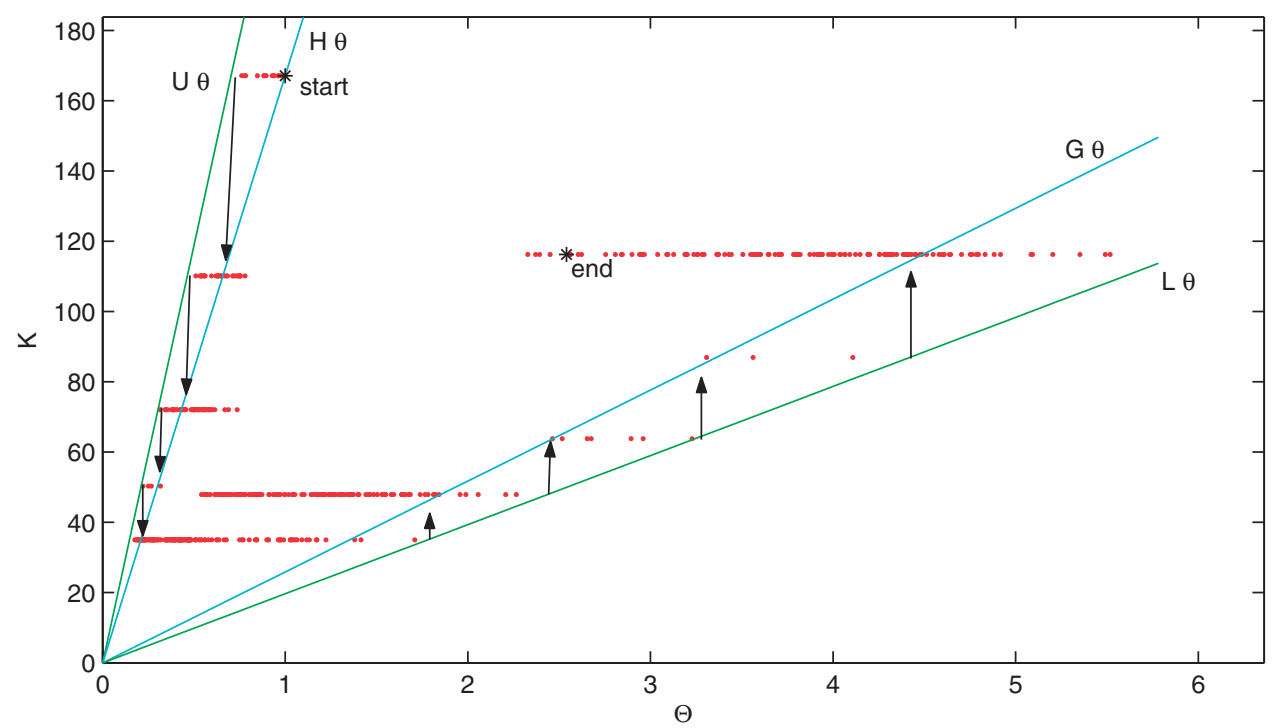

FIGURE 2

Firm evolution

Notes: The figure shows a simulated path of a model firm in the $K-\theta$ plane. The firm parameters are $\gamma=0.85, m=0.4, \delta=0.0, P_{L}=1.0, F_{L}=0.01, P_{U}=0.25, F_{U}=0.01, \mu=0.05, \sigma=0.3, \rho=-0.5$. The pricing kernel has $r=0.04$ and $\sigma_{\Lambda}=0.50$.

Formally, the firm faces an impulse control problem, which is solved in Appendix A. The necessary conditions for an optimal policy are embodied in two value-matching conditions (VMCs) and four smooth-pasting conditions (SPCs). The key feature that keeps the model tractable is that the problem reduces to a single-state variable. If, following Cooper (2006), we define $Z \equiv K / \theta$, then $Z$ is sufficient to summarize the firm's investment opportunities.

Intuitively, because of the frictions, the firm pursues a discrete adjustment policy for $K$ that turns out to be scale-invariant due to the the homogeneous nature of the cost structure and the multiplicative productivity process. With a given level of $K$, it will invest up to $K^{\prime}>K$ only when productivity attains some level $\theta_{L}(K)$. But, once at $K^{\prime}$ the firm faces an identical environment scaled up by the ratio $K^{\prime} / K$. It follows that both $\theta_{L}$ and $K^{\prime}$ are proportional to $K$. By a similar argument, disinvestment will occur only when $\theta$ falls to some $\theta_{U}$ proportional to $K$ and the disinvestment will lower assets to some $K^{\prime \prime}$ also a fixed fraction of the prior $K$. The firm's problem is to choose the four ratios $\theta_{L} / K, K^{\prime} / K, \theta_{U} / K, K^{\prime \prime} / K$ to maximize the expected discounted sum of future profits under the risk-neutral measure. Equivalently the four constants correspond to four points on the $Z$-axis: investment happens at the lower boundary $Z_{t}=L=K / \theta_{L}$ and moves the firm to $Z_{t}=G=\left(K^{\prime} / K\right) L>L$; disinvestment happens at the upper point $Z_{t}=U=K / \theta_{U}$ and moves the firm to $Z_{t}=H=\left(K^{\prime \prime} / K\right) U<U$. The firm thus lives on the interval $[L, U]$. In terms of the original variables, the firm's path in the $K-\theta$ plane, depicted in Figure 2 describes oscillations along lines of fixed $K$ between two rays $K=U \theta$ and $K=L \theta$ with jumps up and down to the interior rays $K=G \theta$ and $K=H \theta$. (The figure sets the depreciation rate to zero for simplicity.)

The effect of adjustment costs on the optimal policy is straightforward. A frictionless firm with no adjustment costs will, given $\theta$, set $K$ to the value $(m / \gamma)^{1 /(\gamma-1)} \theta$ that maximizes the profit function $\Pi$. Denote the $K / \theta$ ratio at this point $Z^{\star}$. Now as fixed or variable investment costs are increased, the firm will choose a smaller value of $L<Z^{\star}$, waiting longer between adjustments. Likewise, either type of cost for disinvestment raises $U>L$. In particular, the ratio of the purchase 
price to the resale price of capital, $P_{L}$ over $P_{U}$, is what captures the capital loss from reversing prior investment.

We note for later the following additional properties of the $Z$ process.

Lemma 1. For any choice of the constants $L, G, H$, and $U$, with $L<U$ and $G, H \in(L, U)$, if the firm is infinitely lived $(\eta=0)$, then the process $Z$ is stationary and ergodic. The stationary density, $f_{0}(Z)$, has positive support on the interval $(L, U)$. If $\eta>0$ and $Z_{0} \sim f_{0}$, then $Z_{t}$ is stationary on $[0, \tau]$ where $\tau=\inf _{t}\left\{N_{t}=1\right\}$ is the firm's obsolescence time.

Similar models have been widely employed in the corporate investment literature, and the features of the optimal policy are well understood from previous work. The focus of this article is on the asset pricing implications of optimal firm behaviour. There is a very large literature that uses real options models in asset pricing applications. An excellent recent overview can be found in Kogan and Papanikolaou 2012). Our contribution is the explicit characterization of the risk premium via closed-form solutions in a setting that is rich enough to encompass a number of dimensions of firm properties 10 The main results are contained in the following propositions whose proofs appear in Appendix A.

Proposition 1. The firm's optimal policy is characterized by the impulse adjustment described by the points on the $Z$ axis $L, G, H$, and $U$ that are determined by a system of six equations given in the appendix. Under the optimal policy, the value of the firm can be written $J(K, \theta)=\theta V(Z)$.

Consider the candidate solution:

$$
V(Z)=A Z^{\gamma}-S Z+D_{N} Z^{\lambda_{N}}+D_{P} Z^{\lambda_{P}}
$$

where

$$
\begin{gathered}
A=\frac{1}{\hat{r}+\gamma \delta+(\gamma-1) \mu^{R N}-\frac{1}{2} \gamma(\gamma-1) \sigma^{2}} \\
S=\frac{m}{(\hat{r}+\delta)}
\end{gathered}
$$

and

$$
\lambda_{P, N}=\frac{b \pm \sqrt{b^{2}+2\left(\hat{r}-\mu^{R N}\right) \sigma^{2}}}{\sigma^{2}}
$$

where

$$
\begin{aligned}
\hat{r} & =r+\eta \\
\mu^{R N} & =\mu+\rho \sigma \sigma_{\Lambda}
\end{aligned}
$$

and $b=\left(\mu^{R N}+\delta+\frac{1}{2} \sigma^{2}\right)$ and $D_{N}$ and $D_{P}$ are positive constants determined by the system given in the Appendix.

Assuming the above function satisfies the condition $(P) V(Z)>0$, and the parameters satisfy the regularity conditions $(R) \hat{r}>\mu^{R N}>-\delta$, then $\theta V(Z)$ is the value of the firm. The $D_{N} Z^{\lambda_{N}}$ and $D_{P} Z^{\lambda_{P}}$ terms are, respectively, the value of the firm's expansion and contraction options. The terms $A Z^{\gamma}-S Z$ are the value of the firm's assets in place.

10. The most closely related asset pricing results are in Cooper 2006, which covers the case of purely irreversible investment with, however, an incorrectly specified SPC. Guthrie 2011) examines a one-time disinvestment option in a setting similar to ours. Ozdagli 2012) solves a version of Cooper's model that includes debt. 
The firm's market-to-book ratio, J/K, monotonically increases with $\theta$. For sufficiently small contraction costs, the value function satisfies $(B) \frac{d J}{d K}>0$.

While, for the most part, it is not possible to exhibit the mapping from firm parameter values to the six constants- $L, G, H, U$ and $D_{N}, D_{P}$ - that define the solution, we show in the Appendix that $\lambda_{N}<0$ and, further, $\lim _{L \rightarrow 0} D_{N}=0$. That is, if the firm chooses never to invest, the growth option component of firm value is absent. Likewise, we show $\lambda_{P}>1$ and $\lim _{U \rightarrow \infty} D_{P}=0$ : the final term adds value if and only if the firm chooses to disinvest.

The firm's share price, $J$, follows a diffusion on the interior of the inaction region. When the boundary is contacted, $Z$, jumps into the interior, and $J$ jumps as well. However, one of the necessary conditions of optimality for the problem is that the total return experienced by investors on an event of investment or disinvestment is zero. That is, the jump in the share price, is equal to the capital withdrawn or added (times its price). Thus, these events do not constitute a source of risk or affect expected return. The risk premium is purely determined by the elasticity of the share price with respect to $\theta$ risk. The next results characterize the behaviour of the firm's risk premium, denoted $\operatorname{EER}(Z)$.

Proposition 2. The instantaneous expected excess return to the firm's equity on the interval $[L, U]$ is given by

$$
\operatorname{EER}(Z)=\pi_{\theta}\left(1-Z V^{\prime} / V\right)
$$

where $\pi_{\theta} \equiv-\rho \sigma \sigma_{\Lambda}$, is the market price of $\theta$ risk. If the solution $V$ satisfies properties $(P)$ and (B) then the risk premium is bounded:

$$
0<\operatorname{EER}(Z)<\pi_{\theta}
$$

The next proposition characterizes the three components of risk and expected return.

Proposition 3. The risk premium, EER(Z), can be written

$$
E E R(Z)=E E R_{A I P}(Z)+E E R_{E O}(Z)+E E R_{C O}(Z)
$$

corresponding to the risk premium of assets-in-place (AIP), expansion option (EO), and contraction option (CO), respectively. Further, for all parameter values for which $(P),(R)$, and (B) hold, we have

$$
E E R_{A I P}>0, \quad E E R_{E O}>0, \quad E E R_{C O}<0
$$

and

$$
E E R_{A I P}^{\prime}>0, E E R_{E O}^{\prime}<0, \quad E E R_{C O}^{\prime}<0 .
$$

The instantaneous volatility of the stock return is $\operatorname{VOL}(Z)=-E E R(Z) / \rho \sigma_{\Lambda}$. Hence assuming $\rho<0$, the same decomposition and partial derivatives apply to equity return volatility.

The risk of assets-in-place is just the (positive) exposure of current profits to productivity shocks. With quasi-fixed costs, this exposure increases with operating leverage, which raises risk as productivity declines. The option to expand increases risk because it confers the right to take on further productivity risk, in exchange for (riskless) cash. Just like a call option on a stock, the options' sensitivity to the underlying $\theta$ shocks increases as the likelihood of exercise increases. Likewise, the contraction option has the properties of a put option: the right to dispose of risky assets (and receive riskless cash). The put has negative exposure to the underlying $\theta$ shocks, which becomes more negative as the likelihood of exercise increases. 
Thus, while the risk from assets-in-place creates an operating leverage effect that monotonically decreases with profitability (increases with $Z$ ), the risk from both real options rises with profitability (or declines with $Z$ ). That is, the opposing forces of operating leverage and real option effects on risk and expected return are the central asset pricing characteristic of the model.

The superposition of the three components produces a characteristic sine-like curve, when plotted against profitability, with a concave segment followed by a convex one (see Figure 1 . As noted in the introduction, the implication of this (typically) nonmonotonic shape is that the relation between profitability and expected return is, in general, ambiguous. One can, however, observe that the relation is more positive near both the upper and lower endpoints of the profitability range as either the expansion and contraction options become closer to exercise. This is the model's primary implication about within-firm variation in risk. It is a consequence of the relative curvatures of the two effects. The effect of operating leverage on risk is close to linear, whereas contraction and expansion options have (respectively) concave and convex effects on risk.

While the concave/convex pattern is very general, the precise shape of the expected return function may vary substantially depending on the firm's specific parameters. Thus the implications about cross-firm variation are less easy to summarize 11 However, the intuition behind the most important comparative statics still follows from the tension between the opposing forces of operating leverage and real option on risk premia. Thus, parameter configurations that increase the value of real options (e.g. with higher volatility, $\sigma$ ) lead to an increasingly positive slope of expected excess return, EER, as a function of the market-to-book ratio, $Q$. Configurations that feature stronger operating leverage ( $e . g$. with a higher fixed cost $m$ ) tend to produce an increasingly negative slope. Quantitatively, it turns out that the strongest effects stem from the variable components of the adjustment costs, $P_{U}$ and $P_{L}$. Higher disposal values, $P_{U}$, and lower installation costs, $P_{L}$, can make contraction and expansion options (respectively) significantly more valuable. Put differently, investment flexibility is the key determinant of the average responsiveness of risk to profitability 12

For very low values of $P_{U}$, for example, the slope of the $E E R$ curve will be mainly downwards. This is the essence of the well-known case for irreversibility being behind the value premium: unprofitable stocks are more risky due to their inability to adjust scale downwards. The literature has perhaps not appreciated, however, that for firms with even a mild degree of investment flexibility (i.e. reversibility), the average slope of the EER curve can be positive: equity actually becomes safer as profitability declines even though operating leverage increases 13 Also note that assessing the implications of a parameter configuration for the observed relation between profitability and expected returns (or risk) requires characterizing the range of profitability in which the firm operates, which is largely determined by the (log) growth rate of the state

11. Analytical characterization of the mapping from the parameters to the function is not possible because it depends on the solution to the boundary location problem, which involves an algebraic system of equations that cannot be solved in closed form.

12. Note that, contrary to some common intuition, the model does not in general imply that the level of risk decreases with investment flexibility. While this is true in the case of contraction options, more expansion flexibility $\left(P_{L}\right.$ closer to 1) actually raises average risk. This parallels the result above that $E E R_{E O}>0$.

13. In a similar model, Guthrie 2011) analytically shows the negative dependence of expected returns on operating leverage for the case of a firm with a one-time disinvestment option, but otherwise fixed scale. The intuition in his case is identical to that in our model. Moreover, the idea is related to the effect in Garlappi et al. 2008, and Garlappi and Yan 2011) where firms approaching bankruptcy experience decreasing risk premia if the the absolute priority rule is violated, and hence equity holders can transform a risky (highly levered) claim into less risky cash recoveries. 
variable $Z 14$ Even under largely irreversible investment, for example, one would not expect to observe a negative average relation between $E E R$ and $Q$ unless the parameters also feature low enough growth in profitability such that the firm's $Z$ process will spend a substantial amount of time in the neighbourhood of the upper boundary, $U$.

Given the rich variety of expected return effects, isolating the empirically relevant predictions of the model requires using real data to restrict the plausible range of parameters. That is the subject of the following section. Summarizing this section, to study the relation between profitability and risk or expected return, we introduced a simple and tractable real options model and analysed its dynamic and comparative static implications. The main dynamic implication is that within-firm variation in profitability will have an increasingly positive association with risk and expected return at extreme ranges of profitability. The main comparative static implication is that the sign of the average expected excess return profile varies across firms largely according to their degree of investment flexibility.

\section{CALIBRATION AND IMPLICATIONS}

We have seen that the juxtaposition of real option and operating leverage effects induces potentially complex expected return patterns. The variety is compounded further by the fact that parameters that have relatively little direct effect on risk-such as depreciation-can still have large effects on what region of the profitability axis the firm inhabits, and thus which riskregion of the $(L, U)$ interval dominates. Given this complexity, there are two goals for this section. The first is to narrow down the model's implications by imposing data-based restrictions from operating characteristics and average return moments. The second is to compare the calibrated implications about risk and expected return to the data.

\subsection{Calibration}

We now turn to the data to discipline the model's predictions. To restrict the scope of the exercise, this section assumes the same parameters characterize all firms. Before starting, we note some caveats about the objectives. The model is designed for its simplicity and transparency. Hence, it can serve as a useful illustration of the linkages between investment, risk, and return. As such, it omits many important characteristics of real firms and their environment. For example, firms have a multitude of real options on a number of different projects, and investment is in practice not as lumpy as it is in a timing model like ours. Firms are capitalized by debt and equity, and face financing frictions which induce cash holdings. Finally, we omit many firm-specific and macroeconomic state variables that have been incorporated elsewhere. Our aim here is not to argue that the model offers the best depiction of the data, even within the neoclassical family. Rather the goal is to deduce parameter restrictions that pin down the model's risk and expected return implications quantitatively.

Our calibration proceeds in three steps. First, we fix the economy-wide parameters based on comparable numbers in related studies. Next, we fix several of the firm-specific parameters that govern the stochastic properties of the firm. Again, we appeal to the related literature to identify most of these. For others, we use values directly implied by observables in our sample of firm-year observations. Finally, for the parameters that govern the firm's adjustment and operating costs, we estimate the parameters via a method of simulated moments targeting the equity premium, the investment and disinvestment rate, average profitability, mean quasi-fixed costs, and the mean and

14. From Itô's lemma, the growth rate of $\log (Z)$ is $-\left(\mu+\delta-\frac{1}{2} \sigma^{2}\right)$. 
TABLE 1

Baseline parameterization

\begin{tabular}{lcc}
\hline Parameter (symbol) & Value & Source \\
\hline Panel A: Economywide parameters & & Fixed (literature) \\
\hline Risk-free interest rate $(r)$ & 0.01 & Fixed (literature) \\
Volatility of the pricing kernel $\left(\sigma_{\Lambda}\right)$ & 1.35 & Fixed (data) \\
Cross-firm productivity correlation $\left(\rho^{(m)}\right)$ & 0.57 & Fixed (literature) \\
\hline Panel B: Firm stochastic parameters & & Fixed (literature) \\
\hline Returns to scale $(\gamma)$ & 0.78 & Fixed (data) \\
Idiosyncratic obsolescence rate $\left(\eta_{I}\right)$ & 0.03 & Fixed (data) \\
Volatility of the productivity process $(\sigma)$ & 0.61 & Fixed (data) \\
Correlation of pricing kernel and productivity $(\rho)$ & -0.17 & Fixed (data) \\
Depreciation rate $(\delta)$ & 0.044 & 0.146 \\
Growth rate of productivity $(\mu)$ & & Fit \\
\hline Panel C: Firm cost parameters & & Fit \\
\hline Quasi-fixed cost $(m)$ & 0.0669 & Fit \\
Purchase price of capital $\left(P_{L}\right)$ & 1.5626 & Fit \\
Fixed cost for purchases $\left(F_{L}\right)$ & 0.0005 & Fit \\
Resale price of capital $\left(P_{U}\right)$ & 0.1345 & 0.0077 \\
Fixed cost for sales $\left(F_{U}\right)$ & &
\end{tabular}

Note: The table lists the parameter values for the baseline model calibration. See Appendix C for a full description of the methodology.

variance of book-to-market. Details of this estimation and the sources in the literature governing our choice of fixed parameters are described in Appendix $C 15$ The result of this procedure is the baseline parameterization shown in Table 1

Given this parameterization, sample properties can be computed by solving for the firm value function $V(Z)$ and optimal policy variables, $L, G, H, U$, and then simulating the stationary distribution of $Z$ implied by the optimal policy 16 Averages of profitability, investment, etc., can then all be evaluated with respect to this distribution. The model is simulated with daily time steps and all quantities are cumulated or re-sampled at lower frequency for comparison with their empirical counterparts. (Some properties, such as the depreciation rate and the Sharpe ratio, are immediately available from the parameters and require no simulation.) Table 2 compares the baseline parameterization to 15 statistics computed in the data. The financial statistics come from CRSP, and the operating statistics come from COMPUSTAT 17 The operating variables are scaled by assets and are measured annually.

Panels A and B reveal that the baseline specification somewhat overshoots the average bookto-market ratio, equity premium, profitability, and quasi-fixed costs. These discrepancies are small economically. Restricting the estimation to match the data exactly on each of these dimensions does not result in a fit that differs perceptibly in terms of our subsequent conclusions regarding risk and expected return. The baseline case closely matches the range of the book-to-market ratio and the disinvestment rate. The table also shows four alternative estimations that employ the same fixed parameters but re-fit the cost parameters. The first case imposes effective irreversibility by

15. The reason for not estimating all the parameters is tractability. Each candidate model's solution requires both a non-linear optimization and a simulation to compute moments. Moreover, the region of the parameter space to be searched is defined by the non-linear regularity conditions described in Section 2 By fixing the parameters governing the dynamics of the exogenous process, these restrictions reduce to linear bounds.

16. Recall that even though $K$ and $\theta$ are non-stationary, the scaled productivity process is stationary.

17. In Appendix $C$, we describe the data sample and the variable construction for the moments in the table. 
TABLE 2

Data and model comparison

\begin{tabular}{|c|c|c|c|c|c|c|}
\hline Moment & $\begin{array}{c}1 \\
\text { Data }\end{array}$ & $\begin{array}{c}2 \\
\text { Baseline }\end{array}$ & $\begin{array}{c}3 \\
\text { Irreversible }\end{array}$ & $\begin{array}{c}4 \\
\text { High fixed cost }\end{array}$ & $\begin{array}{c}5 \\
\text { Low curvature }\end{array}$ & $\begin{array}{c}6 \\
\text { More reversible }\end{array}$ \\
\hline \multicolumn{7}{|l|}{ Panel A: Financial statistics } \\
\hline Mean log book-to-market & -0.3416 & -0.1561 & -0.0960 & -0.2497 & -0.0533 & -0.3717 \\
\hline Std log book-to-market & 1.0317 & 0.9659 & 1.1024 & 1.0025 & 0.9456 & 0.6519 \\
\hline Mean excess return & 0.0574 & 0.0697 & 0.1022 & 0.1069 & 0.0499 & 0.0526 \\
\hline Market Sharpe ratio & 0.3856 & 0.3856 & 0.3856 & 0.3856 & 0.3856 & 0.3856 \\
\hline Mean firm Sharpe ratio & 0.2298 & 0.2298 & 0.2298 & 0.2298 & 0.2298 & 0.2298 \\
\hline \multicolumn{7}{|l|}{ Panel B: Operating statistics } \\
\hline Mean investment & 0.1365 & 0.0240 & 0.0288 & 0.0329 & 0.0143 & 0.0244 \\
\hline Mean disinvestment & 0.0196 & 0.0198 & 0.0260 & 0.0285 & 0.0101 & 0.0200 \\
\hline Mean profitability & 0.0937 & 0.1379 & 0.1300 & 0.1320 & 0.1589 & 0.1380 \\
\hline Mean quasi-fixed costs & 0.0362 & 0.0662 & 0.1194 & 0.1500 & 0.0415 & 0.0290 \\
\hline Mean depreciation & 0.0437 & 0.0437 & 0.0437 & 0.0437 & 0.0437 & 0.0437 \\
\hline Std sales growth & 0.1345 & 0.1345 & 0.1345 & 0.1345 & 0.1345 & 0.1345 \\
\hline \multicolumn{7}{|l|}{ Panel C: Correlations } \\
\hline Autocorr. of investment & 0.3717 & 0.3621 & 0.3623 & 0.3583 & 0.3834 & 0.3601 \\
\hline Autocorr. of profitability & 0.5129 & 0.9684 & 0.9520 & 0.9374 & 0.9599 & 0.9717 \\
\hline Corr. of investment and return & 0.1666 & 0.2532 & 0.2093 & 0.2319 & 0.1979 & 0.2644 \\
\hline Corr. of investment and $Q$ & 0.1607 & 0.5071 & 0.5189 & 0.5241 & 0.4477 & 0.5090 \\
\hline
\end{tabular}

Notes: This table compares firm statistics from CRSP/COMPUSTAT during the 1960-2009 period (column 1) to the statistics of model firms for the simulated stationary distribution (columns 2-6). Operating variables are scaled by assets and are measured annually. See Appendix $\mathrm{C}$ for variable definitions. The column labelled Baseline uses the parameters in Table 1 The next four columns show restricted models where, respectively, $P_{U}=0, m=0.15, \gamma=0.7$, and $P_{U}=0.5$ are imposed. All the fixed parameters are the same for these cases while the cost parameters are re-fit.

enforcing $P_{U}=0$, the second imposes high operating leverage by enforcing $m=0.15$, the third lowers the curvature of the production function to $\gamma=0.70$, and the fourth raises the resale price to $P_{U}=0.5$. While these restrictions each offer some improvements, they are not close, statistically, to the best fit benchmark case.

From the third column, the impact of irreversibility is that the firm spends too much time in low productivity states since it delays disinvesting to minimize the adjustment costs. While this helps slightly with average profitability, the fitted model raises the fixed cost parameter to help offset the investment delay (high fixed costs increases the incentive to shed capital in unprofitable states). The combination of high operating leverage and high adjustment costs makes equity riskier. This leads to lower valuation (log book-to-market is too high) and an implausibly large equity premium.

The case with high $m$ similarly features too high an equity premium, although now the firm sheds capital sooner because the fitted value of $P_{U}$ is higher. The lower curvature case, by contrast, has low operating leverage and somewhat underfits the equity premium. Low fixed costs raise average profitability, but also delay disinvestment. The firm again spends too much time in low $Q$ states.

From the last column, we see that using a higher resale value enables the model to better fit the average book-to-market ratio and the equity premium. The main deficiency of this case is that, since firms adjust quickly, the cross-section has a counterfactually narrow range of book-to-market ratios.

The most notable failing of the model (in all cases) is an inability to come close to matching the average investment rate. To get investment to the observed level requires a very high productivity growth rate, $\mu$, which entails counterfactually high average $Q$ and counterfactually low range of $Q$ 
(as well as zero disinvestment and very high ROA). The model's difficulty on this dimension stems from the assumption that all firm-scale adjustments are subject to the non-convex cost structure described in Section 2. The problem can be readily resolved by assuming a baseline level of non-discretionary maintenance investment flow, $i$, on the order of magnitude of the depreciation rate. This flow would enter the profit function (equation (10) as an additional quasi-fixed cost, but would not otherwise affect the model solution.

In Panel C, we follow Kogan and Papanikolaou 2013; 2014 and examine autocorrelations and correlations that link financial and operating variables. The fitted cases delilver the correct autocorrelation in investment rates. Since the model lacks any transitory shocks to profits, all the cases naturally overstate its autocorrelation. The cases also overstate the correlations between investment and $Q$ and lagged stock returns. The lower correlations in the data reflect the presence of many additional state variables (both permanent and transitory) omitted from the model that affect investment.

Despite the remaining moment discrepancies in the baseline case, the positive result of the exercise is that we are able to obtain meaningful restrictions on the key model parameters using aggregate U.S. firm accounting and financial statistics without requiring micro-level observation of adjustment costs or investment behaviour.

Figure 3 shows the risk premium for the baseline calibration plotted against quantiles of the distribution of profitability or market-to-book (because the two are monotonically related). For these parameters, the convex and concave regions deduced in Section 2 are distinctly present. Moreover, the calibration implies a mostly increasing expected return profile due to the prominence of real option effects relative to operating leverage effects.

The significant influence of expansion and contraction options on systematic risk is a robust conclusion of the exercise that is largely insensitive to choices in the calibration. To illustrate, Figure 4 varies parameters that affect the relative importance of options and operating leverage by factors of two from the baseline values.

The top two panels make real options substantially more costly to exercise by dividing $P_{U}$ by two (upper left) and multiplying $P_{L}$ by two (upper right). From the left panel, even when 93.3\% of the value of installed capital is lost upon disposal, the contraction option continues to significantly attenuate the influence of operating leverage and the average slope of the risk profile is still upwards. Note that as $P_{U}$ approaches zero, the risk profile becomes U-shaped, not monotonically downward sloping, due to the remaining importance of the expansion option 18 So, even with no reversibility, operating leverage will still only be a dominant effect if also the firm has negative productivity growth so that it stays in the low $Q$ region 19 From the right panel, doubling investment costs delays the exercise of expansion options, shifting the right endpoint further to the right. The shape of the risk profile is largely unaffected.

The middle left panel doubles the fixed cost of of production, $m$. This raises the left half of the graph, where operating leverage is larger, but not enough to change the basic shape. The middle right panel attempts to diminish the value of real options by doubling the firm obsolescence rate, $\eta I$, lowering its expected life. This somewhat shrinks the range of $Q$ over which the firm operates, but does not increase operating leverage. A similar conclusion applies to the bottom right panel, where the firm's systematic risk has been doubled, which lowers the risk-neutral productivity growth rate. This succeeds in diminishing the value of the expansion option, but increases the value of the contraction option.

18. The discussion of case 3 in Table 2 above highlights the counterfactual empirical properties of the extreme case of $P_{U}=0$.

19. Such firms would also quickly shrink in scale and ultimately vanish. 


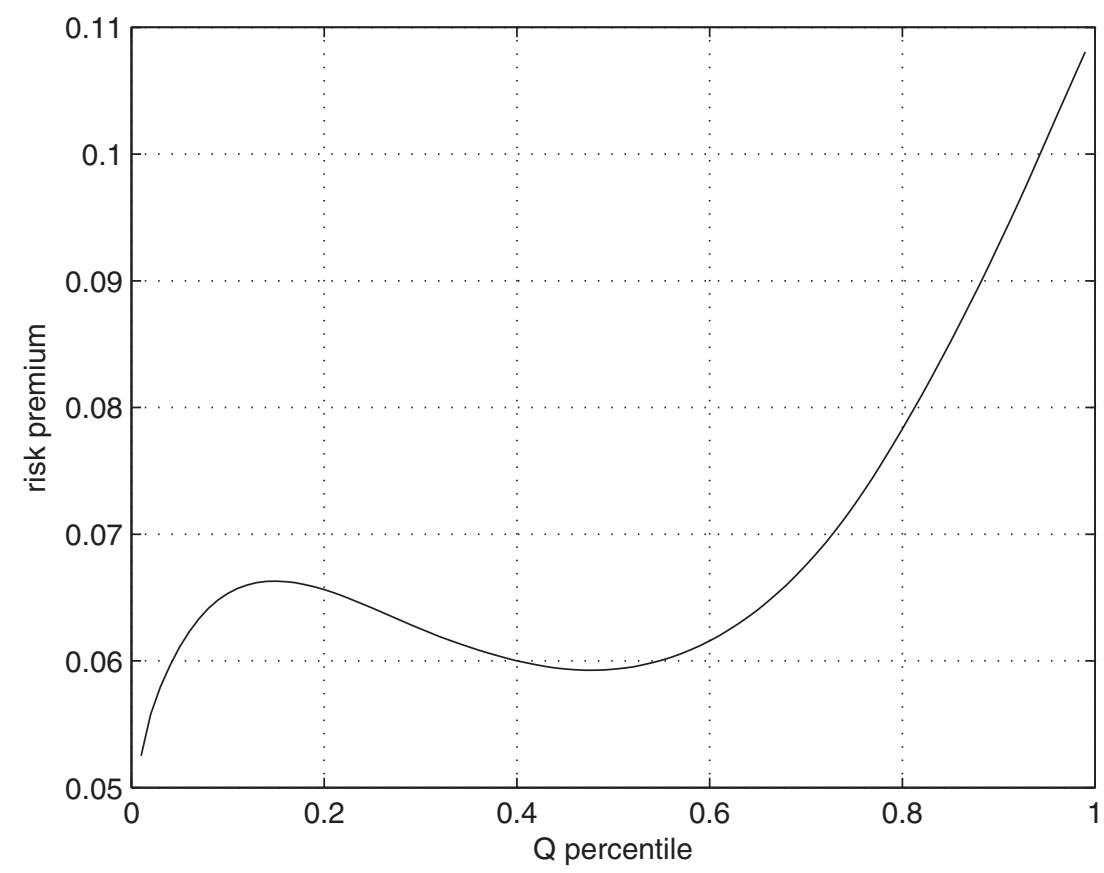

FIGURE 3

Baseline calibration

Note: The figure shows the risk premium for a firm in the baseline calibration plotted against percentiles of the stationary distribution of profitability or market-to-book $(Q)$.

Finally, the bottom left panel cuts the volatility of productivity shocks, $\sigma$, in half. This greatly lowers the value of both real options. As discussed in the Appendix, our baseline value is chosen to match the volatility of firm-level sales (and productivity). Very few firms have volatility of sales as low as the value (less than 7\% per annum) implied by the figure. While the risk profile is effectively flat in this case, the convex and concave regions due to the real options are still apparent and operating leverage effects are no more important.

In sum, in the context of our model, parameterizations which do not have prominent real option effects in firm risk will be the exception rather than the rule. In particular, downward sloping return profiles that have been suggested in the literature would appear to require stepping away from the data on several dimensions at once, for example, by combining very low volatility with the knife-edge case of total irreversibility.

\subsection{Testable implications}

Having identified a plausible region of the parameter space, this section examines the distinctive quantitative implications of the baseline calibration for conditional risk and return measures, and compares them to the data.

3.2.1. Return patterns. Figure 3 above verifies the conclusion from Section 2 of an increasingly positive association between risk or expected return and profitability at the extreme ranges of profitability. This slope pattern provides the basis for a falsifiable test via the implied autocorrelation function. To see this, note that a firm on an upward-sloping segment of the curve 

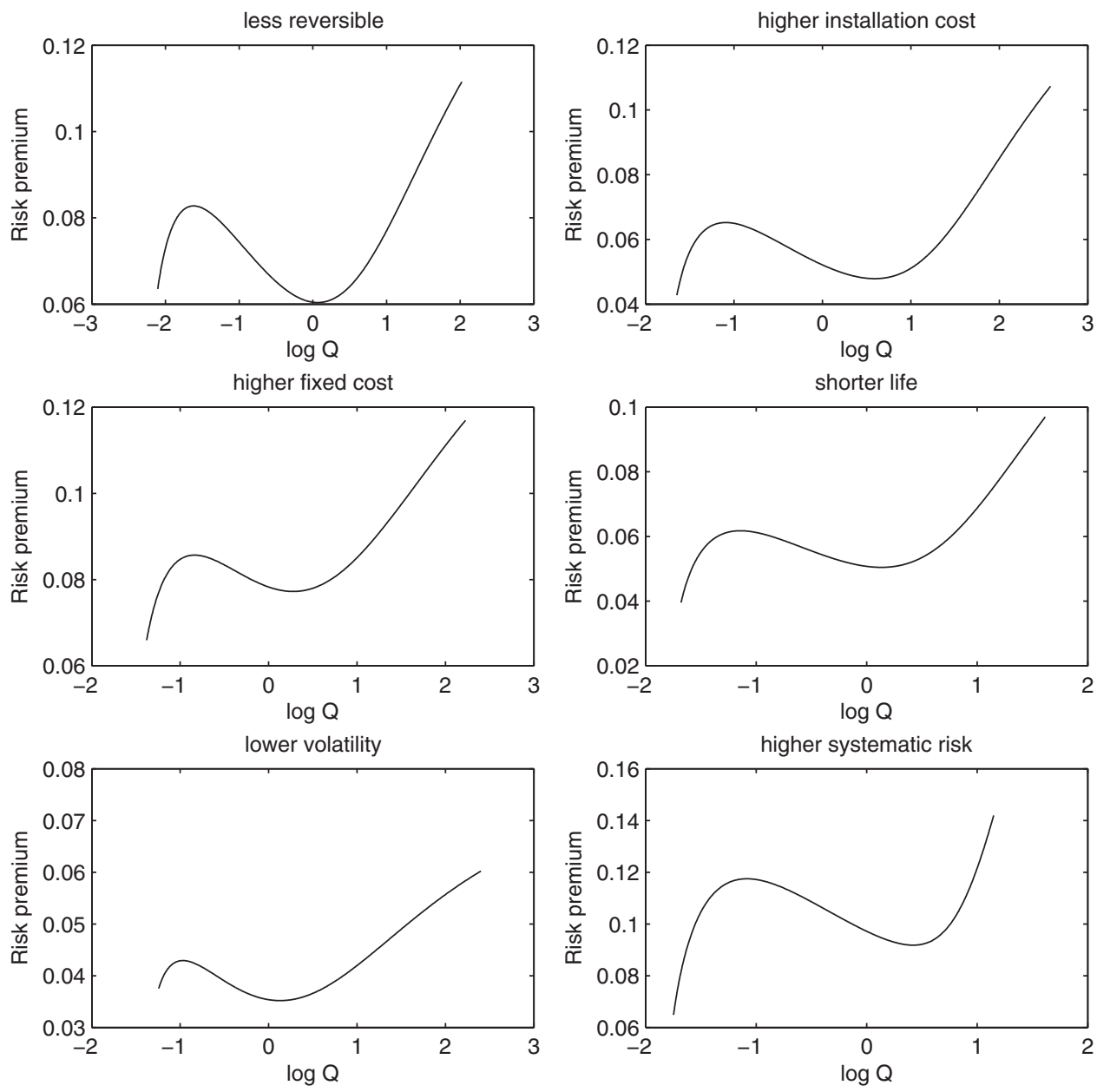

FIGURE 4

Parameter variation

Notes: The figure shows the risk premium for six perturbations by factors of two from the baseline calibration plotted against the $\log$ market-to-book ratio. From top to bottom and left to right, the parameters are $P_{U}=0.067, P_{L}=3.12$,

$$
m=0.134, \eta_{I}=0.06, \sigma=0.305 \text {, and } \rho=-0.34 \text {. }
$$

will find its expected excess returns lower after bad news (a shift to the left) and higher after good news (to the right). This implies that realized returns lead to changes in expected returns in the same direction, i.e. positive return autocorrelation. Likewise, a firm that finds itself on a downward-sloping part of the curve will display the opposite effect, changes in expected returns responding negatively to realized returns. Because the model features alternating upward and downward (or less upward) sloping regions, it thus predicts a conditional time-series effect: return autocorrelation that goes from decreasing to increasing as productivity increases. To our knowledge, there is no prior examination of return autocorrelation as a function market-to-book (or profitability) in the literature.

To make the hypothesis more precise, the instantaneous autocorrelation function in the model may be characterized by the change in conditional mean, $E E R^{\prime}(Z)$ for a given realized 

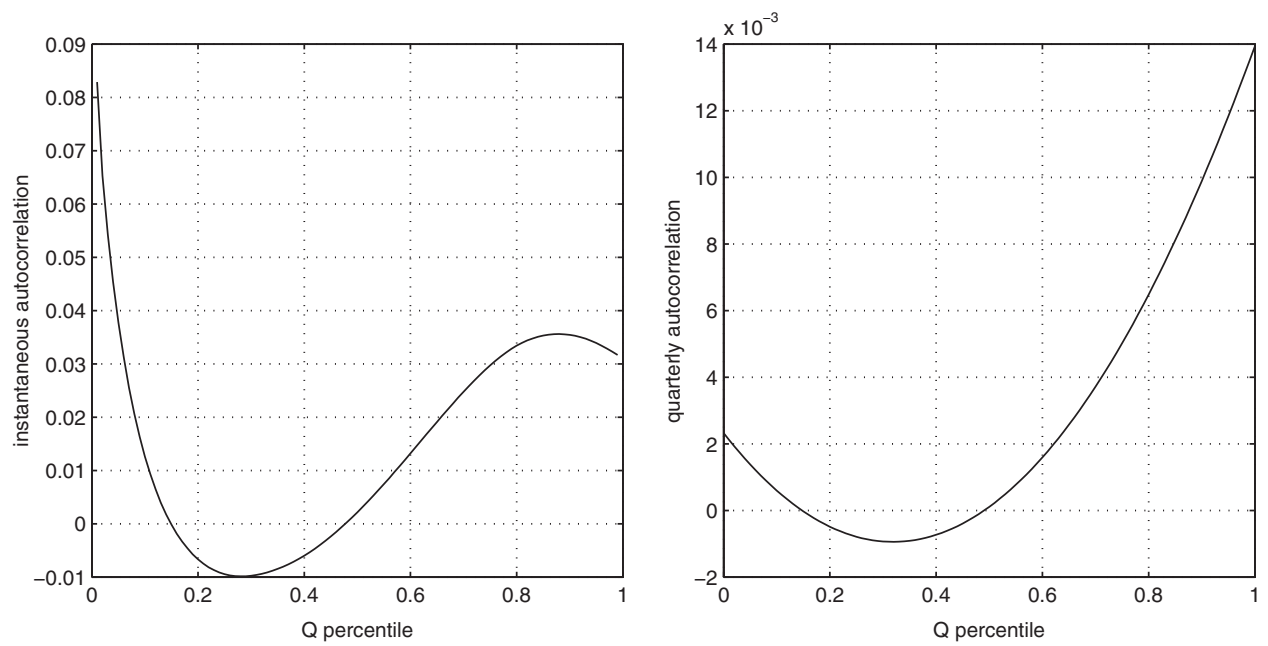

FIGURE 5

Conditional autocorrelation function

Notes: The left panel shows the instantaneous autocorrelation function for the baseline calibration. Also for the baseline parameterization, the right panel shows the quarterly autocorrelation fitted in model simulations conditioning on two powers of the lagged market-to-book ratio (in percentile rank).

return, $V^{\prime}(Z) / V(Z)$, which we can evaluate in closed form 20 In our notation, the instantaneous autocorrelation function is

$$
A C F(Z)=-\rho \sigma \sigma_{\Lambda} Z \frac{V^{\prime}}{V}\left[1+\frac{Z V^{\prime \prime} / V^{\prime}}{1-Z V^{\prime} / V}\right] .
$$

This function, plotted for the benchmark case in left-hand panel of Figure 5 exhibits the alternating positive, negative, and positive regions of autocorrelation. The exact location of the increasing and decreasing regions can vary with the parameter choices (and not all cases actually go negative). However, the switch from a decreasing to an increasing function is always a predominant qualitative feature of the curve. Thus, the key feature that we wish to test for is an interior minimum in the autocorrelation function. While the baseline case does not literally imply a quadratic function, in the context of a quadratic approximation, the hypothesis is equivalent to testing for positive curvature.

Because the mechanism behind this prediction is common across parameterizations, we test for it in a single specification. Hence, we run a pooled regression using the CRSP/COMPUSTAT universe between 1960 and 2009 to maximize statistical power. Because different firms operate in different profitability ranges (in the model and in the data), we estimate an autocorrelation response that is conditional on productivity relative to each firm's industry distribution. The primary specification is:

$$
r_{i, t+2}=a+\left\{b_{0}+b_{1} Q_{i, t}+b_{2} Q_{i, t}^{2}\right\} r_{i, t+1}+\epsilon_{i, t+2}
$$

where $r_{i, t+j}$ denotes firm $i$ 's stock return from time $t+j-1$ to time $t+j, Q_{i, t}$ is firm $i$ 's marketto-book ratio at time $t$ expressed as a within-industry percentile. The reported estimations use

20. This definition follows Sagi and Seasholes 2007). Note that the sign of this expression is solely determined by the numerator as per the intuition in the previous paragraph. The sensitivity of firm value to $Z$ in the denominator is always negative. The sensitivity of $E E R$ to $Z$ is minus its sensitivity to $Q$ since $Q$ is monotonically decreasing in $Z$. 

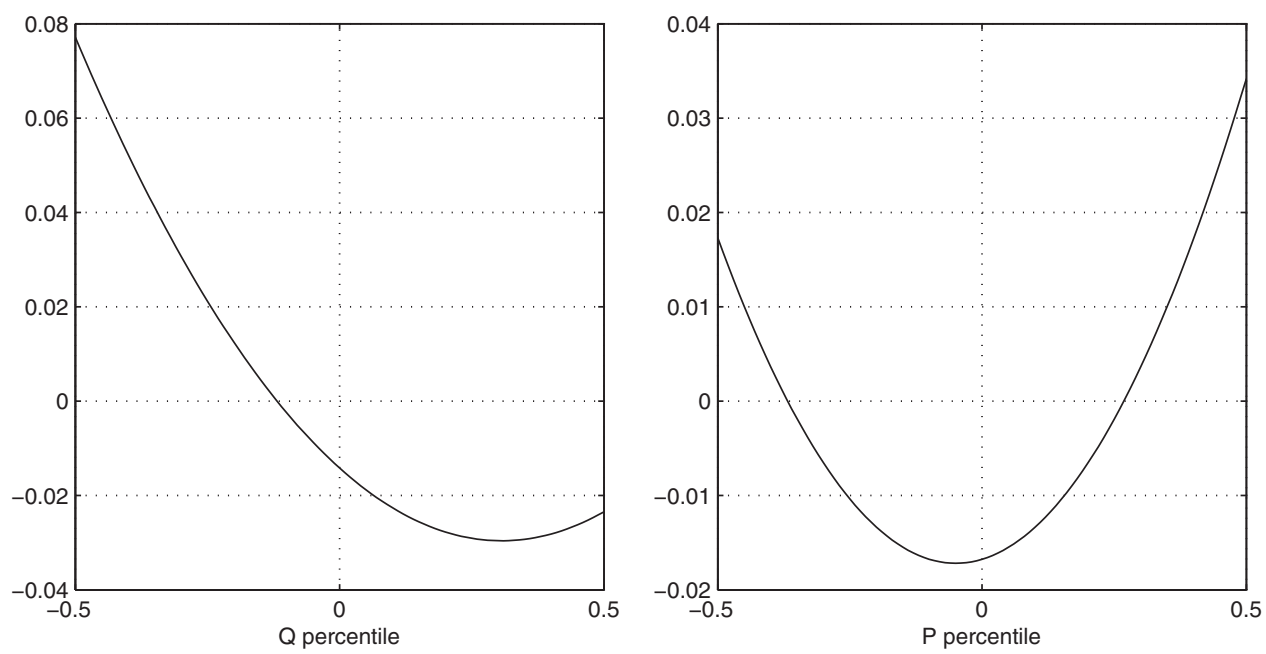

FIGURE 6

Conditional autocorrelation estimates

Notes: The figure shows conditional autoregression coefficients for quarterly stock returns (estimated via specification

6), conditional on market-to-book $(Q)$ in the left panel and profitability $(P)$ in the right panel. The conditioning variables are measured at the start of the period of the lagged return and are expressed as within-industry percentiles.

The horizontal axis centred around the median of the respective distributions. The sample period is 1960-2009.

non-overlapping quarterly stock returns. To deal with cross-firm heteroscedasticity, we employ weighted least squares (WLS) with inverse market capitalization weights. Standard errors are clustered at the industry-date level 21

We employ both the market-to-book ratio $(Q)$ and profitability $(P)$ as conditioning variables. Although the two are equivalent under the model, in the data they are not. Theoretically the implication for $Q$ may be cleaner since profitability contains a substantial transitory component that is absent in the model. However, $P$ is a pure operating statistic, and does not contain any component of market prices. Hence, any conditioning power it contains may be regarded as stronger evidence of real effects.

Results for the empirical tests are plotted in Figure 6 The figure shows the fitted conditional quarterly autocorrelation functions $b_{0}+b_{1} Q+b_{2} Q^{2}$ and $b_{0}+b_{1} P+b_{2} P^{2}$. (The horizontal axes are centred around the medians.) Both plots exhibit a pattern consistent with the model's prediction of a function switching from decreasing to increasing. Formally, the $t$-statistic for $b_{2}>0$ is strongly significant for both $Q$ and $P$ conditioning (Table 3 Panel A). For comparison, we run the same regression in simulated data from the benchmark model. The resulting curve is shown in the right panel of Figure 5

Graphically, the plot for $Q$ (right panel in Figure 6) resembles the baseline case's instantaneous function (in the left panel of Figure 5) in having a peak near lowest $Q$ values. The fitted curve clearly exhibits an interior minimum, although the upward sloping region is less pronounced and the sign does not switch back to positive. For $P$, the fitted plot exhibits distinct positive, then negative, then positive regions. Note that in both curves the conditional autocorrelations are economically large, e.g. ranging over $\pm 2 \%$ in quarterly returns. These are actually larger than, though comparable to, the equivalent range from the model simulation (about 1.5\%) in the right

21. The results are statistically similar using time fixed-effects or excess stock returns. 
TABLE 3

Conditional covariance evidence

\begin{tabular}{|c|c|c|c|c|}
\hline \multicolumn{5}{|c|}{ Panel A: Autocorrelation } \\
\hline Conditioning variable & $b_{0}$ & $b_{1}$ & $b_{2}$ & \\
\hline $\begin{array}{l}Q \\
P\end{array}$ & $\begin{array}{c}0.0750^{* * *} \\
(1.34 \mathrm{e}-2) \\
0.0172 \\
(1.65 \mathrm{e}-2)\end{array}$ & $\begin{array}{c}-0.00260^{* * *} \\
(5.03 \mathrm{e}-4) \\
-0.00155^{* *} \\
(6.28 \mathrm{e}-4)\end{array}$ & $\begin{array}{l}1.61 \mathrm{e}-5^{* * *} \\
(4.72 e-6) \\
1.72 \mathrm{e}-5^{* * *} \\
(5.54 \mathrm{e}-6)\end{array}$ & \\
\hline \multicolumn{5}{|l|}{ Panel B: Market beta } \\
\hline Conditioning variable & $\beta_{0}$ & $\beta_{1}$ & $\beta_{2}$ & $\beta_{3}$ \\
\hline$Q$ & $\begin{array}{l}1.0365^{* * *} \\
(0.0546)\end{array}$ & $\begin{array}{c}0.1952 \\
(0.1240)\end{array}$ & $\begin{array}{c}-0.4050^{* *} \\
(0.1907)\end{array}$ & $\begin{array}{r}1.1811^{*} \\
(0.7013)\end{array}$ \\
\hline$P$ & $\begin{array}{l}0.9805^{* * *} \\
(0.0669)\end{array}$ & $\begin{array}{c}0.0090 \\
(0.1099)\end{array}$ & $\begin{array}{c}-0.5450^{* *} \\
(0.2700)\end{array}$ & $\begin{array}{c}2.0202^{* *} \\
(0.9230)\end{array}$ \\
\hline
\end{tabular}

Notes: The table reports results from panel regression (6) and (7) of quarterly stock returns on conditional polynomial functions implied by the model. The top panel estimates the one-lag autocorrelation function conditional on a quadratic function of lagged market-to-book $(Q)$ and return on assets $(P)$. The bottom panel estimates the contemporaneous loading on the CRSP value-weighted index, conditional on the same varibles. The sample period is 1960:Q1 to 2009:Q4. Both panels use weighted least-squares with weights inversely proportional to market capitalization. WLS standard errors, reported below the coefficients, are clustered by industry date. *significance at $90 \%$ level, **significance at $95 \%$ level, $* * *$ significance at $99 \%$ level.

panel of Figure 5 These empirical results represents new evidence of real option effects in stock returns.

The results here relate closely to two other important contributions. Sagi and Seasholes 2007) and Garlappi and Yan 2011) each provide evidence of enhanced momentum profits in restricted samples of stocks motivated by the predictions of real option models. In Sagi and Seasholes 2007), momentum profits are predicted (and shown) to be stronger among firms with more (or cheaper) growth options, while in Garlappi and Yan 2011) momentum effects are predicted (and shown) to be stronger among indebted distressed firms in which equity shareholders effectively hold a disposal option 22 In effect, our model pieces the two types of options together and yields enhanced continuation at both extremes of profitability.

Our time-series tests are, however, conceptually and econometrically different from momentum tests, which reveal cross-firm, rather than within-firm, variation in stock returns. It is thus reasonable to ask whether our calibrated model does, in fact, imply conditional momentum effects and whether the data support the conditional predictions. To explore this question, we build on another recent contribution in Nyberg and Pöyry 2013). These authors examine momentum profits conditional on realized asset growth and find that momentum profits are concentrated among firms that have either realized large asset contractions (i.e. exercised disinvestment options) or that have realized large asset expansions (i.e. exercised investment options). In the context of our model, where asset growth (via disinvestment or investment) occurs discretely and infrequently, we test if similar findings hold for expected asset growth, which is another monotone transformation of the productivity state variable.

22. In unreported results, we examine whether our autocorrelation effect for low profitability levels is distinct from the conditional momentum findings of Garlappi and Yan 2011). Repeating our tests dropping the top quintile of the market leverage distribution to eliminate financially distressed firms yields results almost identical to those in Figure 6 While the mechanism in our model is completely compatible with effects related to violations of absolute priority in default, default risk does not appear to drive our results. 
TABLE 4

Conditional momentum strategy returns

\begin{tabular}{|c|c|c|c|c|c|c|}
\hline \multicolumn{7}{|l|}{ Panel A: Data } \\
\hline \multirow[b]{2}{*}{ Expected asset growth: } & \multicolumn{6}{|c|}{ Momentum } \\
\hline & Loser & 2 & 3 & 4 & Winner & $5-1$ \\
\hline Low & 3.8700 & 7.4616 & 10.7784 & 12.1392 & 17.7696 & 13.8996 \\
\hline 2 & 8.2572 & 10.5084 & 10.7880 & 11.3652 & 16.3344 & 7.8108 \\
\hline 3 & 7.5348 & 9.5376 & 9.5292 & 11.5572 & 13.9620 & 6.7416 \\
\hline 4 & 9.6096 & 10.8060 & 8.9268 & 12.2520 & 16.6392 & 6.8268 \\
\hline 5 & 5.9460 & 9.8580 & 8.8224 & 12.6156 & 15.3528 & 9.2964 \\
\hline 6 & 6.1908 & 9.6864 & 8.8056 & 12.4032 & 14.7168 & 8.6736 \\
\hline 7 & 6.9684 & 8.1876 & 10.6296 & 10.6188 & 15.6408 & 8.6592 \\
\hline 8 & 4.2192 & 6.8592 & 9.2856 & 13.0332 & 17.3052 & 13.0128 \\
\hline 9 & 4.3836 & 9.1848 & 8.5452 & 6.9996 & 16.5660 & 12.2772 \\
\hline High & 0.4764 & 7.0368 & 8.4912 & 11.6256 & 14.0688 & 13.7196 \\
\hline \multicolumn{7}{|l|}{ Panel B: Model } \\
\hline Low & 5.7817 & 5.9844 & 6.2058 & 6.3791 & 6.4941 & 0.7124 \\
\hline 2 & 6.6003 & 6.6007 & 6.5996 & 6.6007 & 6.6048 & 0.0045 \\
\hline 3 & 6.4038 & 6.4018 & 6.4036 & 6.4050 & 6.4040 & 0.0002 \\
\hline 4 & 6.1083 & 6.1110 & 6.1100 & 6.1062 & 6.1095 & 0.0012 \\
\hline 5 & 5.9448 & 5.9446 & 5.9449 & 5.9449 & 5.9450 & 0.0002 \\
\hline 6 & 6.0381 & 6.0346 & 6.0333 & 6.0344 & 6.0343 & -0.0039 \\
\hline 7 & 6.4612 & 6.4529 & 6.4512 & 6.4609 & 6.4683 & 0.0071 \\
\hline 8 & 7.3249 & 7.2922 & 7.2743 & 7.2826 & 7.3215 & -0.0034 \\
\hline 9 & 8.5020 & 8.5967 & 8.6073 & 8.6105 & 8.6451 & 0.1431 \\
\hline High & 9.5574 & 9.7339 & 9.8742 & 10.0230 & 10.3086 & 0.7512 \\
\hline
\end{tabular}

Notes: The top panel shows the average annual porfolio returns (percentage) from a two-dimensional sort of firms according to lagged returns (momentum) and expected asset growth. The sample is the set of all firms in the CRSP/COMPUSTAT intersection from 1960 to 2009, excluding firm-quarters in which the stock price is below \$5. Expected asset growth is defined as the predicted value from a full-sample industry panel regression of asset growth on lagged asset growth, lagged $Q$, and lagged cash-flow. Momentum is the lagged one-year stock return. Returns in each portfolio are value weighted. The bottom panel does the same exercise in a simulated cross-section of 50,000 firm-years for homogeneous firms whose parameters are given in Table 1 The simulation tabulates averages of firm expected excess returns after sorting on 12-month realized return and on distance to the investment boundary.

Table 4 reveals that this is indeed the case. The table follows the design of Nyberg and Pöyry 2013) by reporting realized equity returns to portfolios formed by a two-way sorting procedure. Each month the universe of firms is sorted by lagged one-year return and, independently, by expected asset growth. Expected asset growth is defined as the predicted value from a fullsample industry panel regression of asset growth on lagged asset growth, lagged $Q$, and lagged cash-flow. Momentum is the lagged one-year stock return. Returns in each portfolio are value weighted. Reading across the rows, the top panel verifies that indeed winners outperform losers by a significantly larger amount among firms with either very high or very low expected asset growth.

The bottom panel performs the same sorting procedure in simulated panels of identical firms having the baseline parameter configuration. The result is indeed the same U-shaped pattern in the right-hand column. The model effect is significantly smaller than that observed in the data. The baseline calibration delivers a differential between winner and loser quintiles of less than 100 basis points. However, it very clearly finds no such effect except among firms that are approaching the exercise of their real option to either expand or contract. We return to the magnitude of the model's (unconditional) momentum effects in the Section 4. Here, we conclude that both our 
conditional sorting and our within-firm conditional time-series tests deliver results consistent with the pattern predicted by the calibrated model.

3.2.2. Risk patterns. To this point, we have emphasized the implications of real option effects in expected returns. However, coming from a risk-based theory, analogous implications apply to the conditional risk faced by stockholders. We therefore examine whether there is any supporting evidence in the realized second moments of equity returns 23

It is important to note that, being set in partial equilibrium, the model does not take a stand on the precise nature of the risks that investors care about. The model's predictions all apply to "risk" in the sense of covariance with a generic pricing kernel, $\Lambda$. Identifying the true pricing kernel is beyond the ambition of this article. This poses a dilemma for empirical strategies: tests based on covariances with factors that are not, in fact, priced by investors should not be expected to succeed.

However, the model does suggest a partial solution to the pricing kernel problem via the standard capital asset pricing model (CAPM). Under the model, each firm $i$ 's realized stock return is driven by a single Brownian productivity shock, $d \theta_{t}^{(i)}$ whose covariance with the pricing kernel is $\rho$. Averaging across a large number of stocks, the "market" return should be reasonably correlated with $\Lambda$. This could fail because there could be other common factors across firms' productivity innovations unrelated to $\Lambda$ that would survive aggregation. (The model allows for this via the parameter $\rho^{(m, i)}$.) This could attenuate conditional patterns in market covariances, but conditional expected return patterns should still be mirrored in market beta patterns.

The model implies that systematic risk should follow the identical pattern of expected returns, as plotted in Figure 3 To assess this predictions, we estimate conditional betas in specifications similar to those used to estimate conditional autocorrelations in the previous subsection. Specifically, we condition each firm's market covariance on its own realization of either market-to-book $(Q)$ or profitability $(P)$ in monthly return regressions, as in:

$$
r_{i, t}=\alpha+\left\{\beta_{0}+\beta_{1} Q_{i, t-1}+\beta_{2} Q_{i, t-1}^{2}+\beta_{3} Q_{i, t-1}^{3}\right\} r_{t}^{(M)}+\epsilon_{i, t}
$$

where $r_{t}^{(M)}$ is the return on the CRSP value-weighted index. The cubic form is convenient because the predicted non-linearity can be summarized by the hypothesis that $\beta_{3}>0$. A positive value corresponds to a market covariance whose slope is increasingly positive as $Q$ goes to the high and low ends of its range. We have seen that our benchmark calibration also has a positive slope on average because it features relatively little operating leverage and strong real option effects. We can also assess whether the overall slope of the fitted specification is positive as the difference in functional values at the right and left endpoints.

As with the autocorrelation test, we estimate specification 7 in our pooled sample, using within-industry percentile ranks of $Q$ and $P$. Again, the regressions use weighted least-squares with inverse market capitalization weights and clustered standard errors. The fitted specifications are shown graphically in Figure 7 The shape of estimated conditional beta curves do resemble the shape of the risk curve for the calibrated model. The cubic coefficient is statistically significant at the 5\% level for the $P$ specification and at the $10 \%$ level in the $Q$ specification (Table 3 Panel B). The estimates also imply an economically large degree of variation of risk: nearly a factor of two in both specifications. This is again the same magnitude of variation implied by the baseline parameterization. The fitted cubic curve in the calibrated case, shown in Figure 8 varies from about 0.8 to 1.6 . 

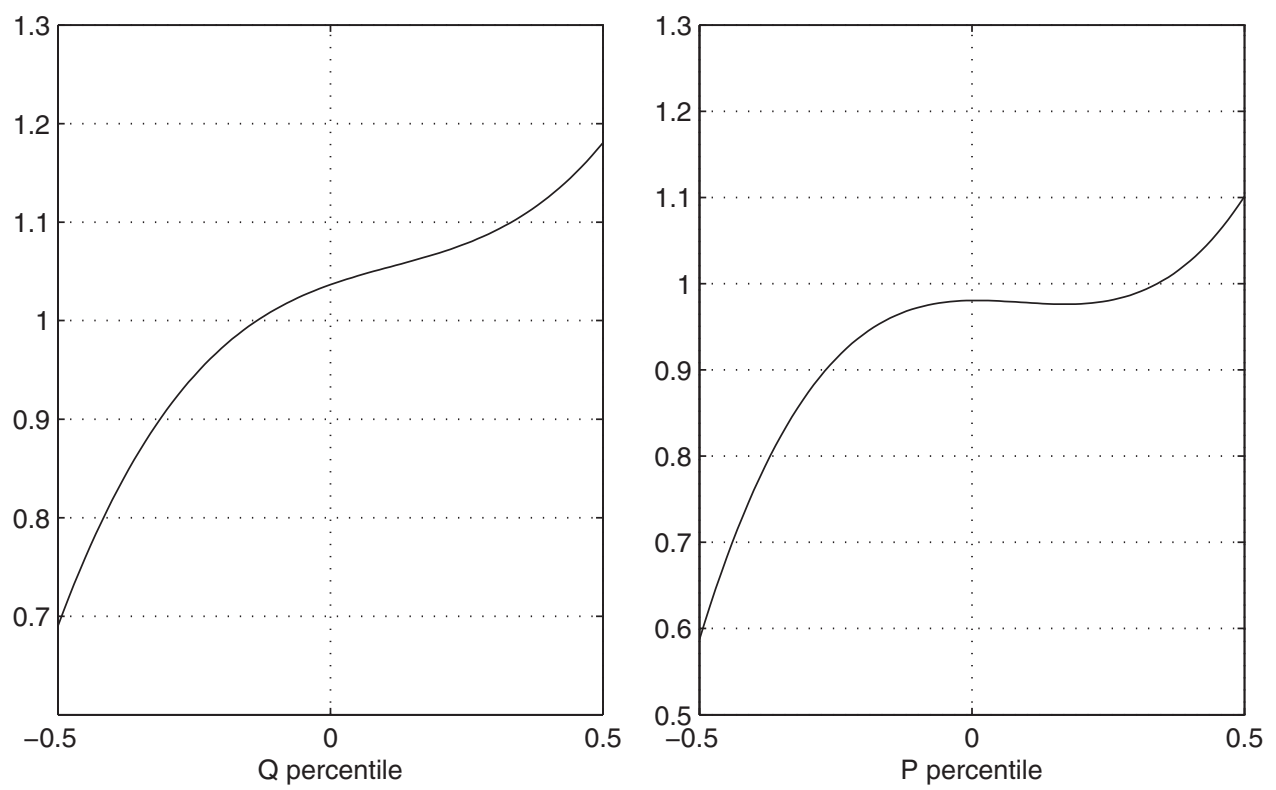

FIGURE 7

Conditional market beta tests

Notes: The figure shows cubic beta functions (estimated via specification 7) plotted against percentiles (centred at the median) of market-to-book $(Q)$ and profitability $(P)$. The sample period is 1960-2009.

In addition, the estimation yields very solid evidence with both conditioning variables that the average slope of the risk curve is positive. The slope over the interval $\left[-\frac{1}{2},+\frac{1}{2}\right]$ is positive if $4 \beta_{1}+\beta_{3}>0$. The $F$-statistic for this hypothesis has $p$-value below 0.01 for $Q$ and 0.02 for $P$. This is the first evidence that we are aware of documenting a positive relationship between equity risk and accounting measures of valuation and profitability. The finding supports the assertion that the unconditional profitability effect in expected returns stems from the risk properties of real options. We now return to the model's unconditional predictions in a multivariate context.

\section{VALUE, MOMENTUM, AND PROFITABILITY}

The empirical tests above showed evidence consistent with the model's prediction of a nonmonotonic return-productivity relation. We now return to the well-known return anomalies discussed in the introduction to explore the model's ability to speak to them.

As described in the introduction, one set of anomalies (including value and investment effects) suggests a downward sloping risk-profitability relation, while another set (including momentum and profitability effects) is more consistent with an upward sloping relation. Our model can feature regions of either slope depending on the relative strength of real option effects (upward) and operating leverage effects (downward). In principle, then, it might allow for the coexistence of seemingly contradictory effects.

As a starting point, we consider the benchmark parameterization from Section 3.1. We first ask what happens if we simulate a cross-section of firms from this parameterization, compute the firm-specific attributes (book-to-market, momentum, and profitability) in each panel in the same way empiricists do in the traditional tests, and then run those tests (e.g. Fama-MacBeth regressions) in the panels. 


\section{HACKBARTH \& JOHNSON REAL OPTIONS AND RISK DYNAMICS}

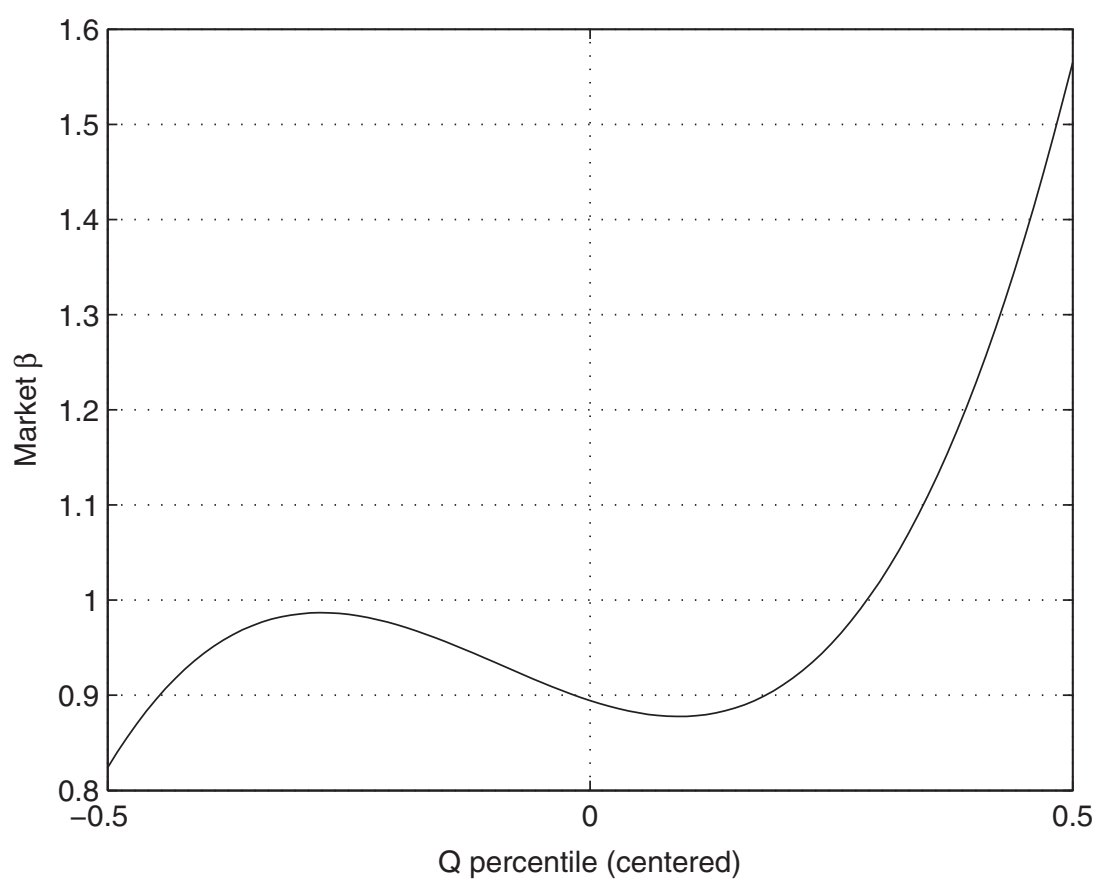

FIGURE 8

Simulated beta tests

Notes: The figure shows the fitted cubic beta plotted against $Q$ percentiles (centred at the median) from estimating 7 in model simulations using the baseline parameter specification.

The answer, shown in Panel A of Table 5, is that the baseline calibration does not make much progress with these anomalies. Since this case features important real option effects and small operating leverage effects, it can deliver a positive profitability premium: expected returns on average rise with $Q$ or $P$, as shown in Figure 3 Indeed, the simulated coefficient is as large as the empirical counterpart in the Panel D24 Conversely, since profitability and valuation are perfectly negatively correlated in the model, the case entails a negative value premium. As foreshadowed by the results Table 4 there is a positive momentum effect, but it is economically small in the univariate specification. Multivariate regressions are not successful at enhancing value and momentum. Although not perfectly collinear, their joint span is not able to capture any of the underlying non-linearity of expected returns in this calibration.

Prior research has used purely irreversible specifications to explain the value effect. But Panel B shows that this is not reproducible using the irreversible case of our model fitted in Section 3.1. The reason is that, while the effects of the contraction option vanishes in this case, there are still strong expansion option effects. Much of the mass of the firm's unconditional distribution is in the high $Q$ region where the risk profile slopes up. As a result, the book-to-market coefficient, while of the right sign, is nowhere near its empirical counterpart. Of course, the profitability effect, its mirror image, has the wrong sign. And the momentum coefficients are effectively zero. Conversely, the case of more reversibility from Section 3.1, shown Panel C, can strengthen both

24. The independent variables are percentile ranks of each characteristic within each month's cross-section of firms. Thus, the coefficient corresponds to the increase in expected return from the lowest to the highest firm on each dimension. Further details of the simulation procedure are given in the table caption. 
TABLE 5

Return anomalies in homogeneous panels

\begin{tabular}{lcccc}
\hline Variable: & 1 & 2 & 3 & 4 \\
\hline Panel A: Baseline & & & \\
\hline Profitability & 0.0022 & & & \\
& $(1.82)$ & & & \\
Book-to-market & {$[0.56]$} & -0.0022 & & -0.0022 \\
& & $(1.38)$ & & $(1.79)$ \\
Momentum & {$[1.00]$} & 0.0009 & 0.0003 \\
& & & $(1.68)$ & $(1.08)$ \\
\end{tabular}

Panel B: Irreversible

\begin{tabular}{lc}
\hline Profitability & -0.0014 \\
& $(1.12)$ \\
Book-to-market & {$[0.94]$}
\end{tabular}

\begin{tabular}{ll} 
Momentum & \\
& \\
\hline Panel C: More Reversible \\
\hline Profitability & 0.0055 \\
& $(2.35)$ \\
Book-to-market & {$[0.37]$}
\end{tabular}

Book-to-market

$-0.0055$

(2.35)

[1.00]

Momentum
0.0014

(1.12)

[0.68]
0.0015

(1.15)

[0.68]

$-0.0003 \quad 0.0000$

$(0.55) \quad(0.13)$

[0.91] [0.96]

\begin{tabular}{|c|c|c|c|c|c|}
\hline Momentum & & & $\begin{array}{l}0.0020 \\
(1.92) \\
{[0.51]}\end{array}$ & $\begin{array}{l}0.0001 \\
(0.44) \\
{[0.95]}\end{array}$ & \\
\hline \multicolumn{6}{|l|}{ Panel D: Data } \\
\hline Profitability & $\begin{array}{l}0.0039 \\
(2.06)\end{array}$ & & & & $\begin{array}{l}0.0059 \\
(2.71)\end{array}$ \\
\hline Book-to-market & & $\begin{array}{c}0.0142 \\
(4.76)\end{array}$ & & $\begin{array}{l}0.0196 \\
(6.76)\end{array}$ & $\begin{array}{l}0.0182 \\
(7.34)\end{array}$ \\
\hline Momentum & & & $\begin{array}{c}0.0182 \\
(5.81)\end{array}$ & $\begin{array}{l}0.0235 \\
(8.29)\end{array}$ & $\begin{array}{l}0.0230 \\
(8.19)\end{array}$ \\
\hline
\end{tabular}

Notes: The table shows the results of Fama and MacBeth 1973) regressions of realized excess stock returns on firmspecific characteristics in 500 simulated panels of 2000 firms observed monthly for 50 years. Profitability and Book-tomarket are beginning-of-period values. Momentum is the lagged 12-month stock return. The independent variables are expressed as percentile ranks within each month's cross-section. The top panel uses the baseline parameters given in column 2 of Table 1 The next two panels use the alternatives shown in columns 3 and 6 of that table. The simulation assumes that firm productivity, $\log Z^{(i)}$ is initially distributed uniformly on $\left[\log \left(L^{(i)}\right), \log \left(U^{(i)}\right)\right]$. The coefficients and $t$-statistics in parentheses are the cross-panel means of the Fama-MacBeth estimation procedure. The numbers in brackets are the fractions of panels in which the corresponding $t$-statistic is less than 1.97. The bottom panel gives the results in the CRSP/COMPUSTAT cross-section used in Section 3. The sample period is 1960-2009.

momentum and profitability effects significantly. However, the value puzzle necessarily gets worse.

Based on the calibration of Section 3 and the results here, we believe that the profitability effect documented by Fama and French 2006) and Novy-Marx 2013) may be largely attributable 
TABLE 6

Return anomalies in heterogeneous panels

\begin{tabular}{lcccccc}
\hline Variable: & 1 & 2 & 3 & 4 & 5 & 6 \\
\hline Profitability & 0.0020 & & & & 0.0159 & 0.0168 \\
& $(3.17)$ & & & $(4.38)$ & $(4.87)$ \\
& {$[0.28]$} & & & 0.0011 & $0.05]$ & {$[0.01]$} \\
Book-to-market & & 0.0008 & & $(1.46)$ & $(3.75)$ & $(4.38)$ \\
& & $(1.18)$ & & {$[0.65]$} & {$[0.16]$} & {$[0.07]$} \\
Momentum & & & 0.0017 & 0.0005 & 0.0006 \\
& & & 0.0015 & $(3.91)$ & $(1.73)$ & $(1.82)$ \\
Beta & & {$[0.16]$} & {$[0.04]$} & {$[0.60]$} & {$[0.59]$} \\
& & & & & 0.0013 \\
& & & & & $(1.51)$ \\
\end{tabular}

Notes: The table shows the results of Fama and MacBeth 1973) regressions of realized excess stock returns on firmspecific characteristics in 500 simulated panels of 2000 firms observed monthly for 50 years. Firms differ in their exposure to systematic risk, having $\rho$ either -0.11 or -0.33 in equal proportions. The obsolescence rate is $6.5 \%$. All other parameters are as given in Table 1 The simulation procedure is as described in the caption to Table 5 The coefficients and $t$-statistics in parentheses are the cross-panel means of the Fama-MacBeth estimators. The numbers in brackets are the proportions of panels in which the corresponding $t$-statistic is less than 1.97 .

to real option effects. However, the results also highlight the limitations of a model in which profitability and valuation are perfectly collinear. The empirical regressions tell us that there is economically meaningful information in the distinction between the two, although its nature is an open question. One way of generating a wedge between them is to include additional state variables, adding shocks to firm uncertainty or expected growth rates, for example. Alternatively, our model is simple and tractable enough to enable analysis of populations of firms that differ in their production and investment technologies, while staying within the single state variable framework. Firms with different production functions (costs, returns-to-scale, etc.) or underlying productivity processes (growth rate and volatility) will have different levels of valuation for the same degree of current profitability. We present two simple examples that highlight the positive possibilities of this approach.

First, following the logic of Berk 1995), we consider a cross-section of firms with different systematic risk, holding total risk constant. In our model, the parameter $\rho$ represents the correlation of the productivity process with the pricing kernel. Table 6 re-runs the regressions in panels of firms with $\rho^{(i)}$ equal to -0.11 or -0.33 . These numbers determine the Sharpe ratios of firms' equity, and imply values well within the range of observed Sharpe ratios across firms.

The first four specifications in Table 6 show magnitudes similar to the homogeneous panels, although the univariate sign on the book-to-market ratio is now correct. Column 5 contains a much stronger result. When profitability and book-to-market are used together, they both become much more positive. Indeed, both are now as large or larger as seen in the corresponding empirical regressions. Here we do see that non-linearities help to explain the coexistence of two positive effect. For any given level or profitability, now there are two types of firms $i$, those with high or low values of $\rho^{(i)}$. The firms with the higher systematic risk naturally have lower valuations and higher risk premia. Hence, the conditional relation, after controlling for the real option effect of profitability is positive.

In column 6, we verify that these results are not an artefact of failure to control for market beta. These regressions include the lagged realized beta in trailing 60-month windows, which closely parallels empirical practice in such tests. While there is a small market risk premium in the model, realized betas are a noisy proxy for the rapidly changing true risk exposures of firms. 
Hence, even though a version of the conditional CAPM holds in this economy, this does not alter the conclusions about the proxying effect of firm characteristics in return regressions.

Secondly, we examine the ability of the model to speak to simultaneous profitability and investment effects. Empirically, firms with high investment rates have low returns in the cross-section (see e.g. Titman et al. 2004). This is clearly related to the value effect, because high valuations reflect strong investment opportunities. Cooper et al. 2008) find that firms' investment rates largely drive the negative relation between asset growth and subsequent returns. Recently, Fama and French 2015) have reported that, in a factor model including profitability and investment factor 25 the explanatory power of the book-to-market factor is subsumed in the cross-section of U.S. stocks. It is possible, then, that investment is the more relevant variable economically. We now demonstrate that panels consisting of firms that differ in their investment rates can reproduce the negative relation between investment and returns.

The investment rate in the model is primarily determined by the average growth rate of productivity per unit capital, $Z^{-1}$, whose percentage drift is $\mu+\delta-\frac{1}{2} \sigma^{2}$. The empirical literature also reports that the anomalously low stock returns to high investing firms is concentrated in small, young firms. In the model, the average firm age is set by the parameter $\eta$, which is the inverse expected lifetime.

Table 7 shows the regressions for panels of firms consisting of equal portions of baseline firms and firms having an average age of 10 years and an unconditional investment rate of $17 \%$ of total assets per year 26 The expected return to the latter type is lower due to the shorter effective duration of their future cash-flows relative to the slower growing, longer lived benchmark firms 27

The results reveal the ability of heterogeneous panels to deliver an economically and statistically significant negative investment premium, both unconditionally and conditional on profitability. Conditional on firm type, the expected returns of both low investment and high investment firms exhibit the same positive association with profitability that we saw in homogeneous panels. As in the previous table, the conclusions in the table are robust to the inclusion of market betas as an explanatory variable.

The findings here are meant to point a way forward for the investment-based asset pricing research programme. The heterogeneous panels - each exploiting merely two firm types-are intriguing and demonstrate the ability of the model to speak to the coexistence of seemingly contradictory effects in the data. The logical next step is to estimate the actual heterogeneity of firm characteristics. The tractability of the model means that simulations can easily accommodate distributions of very high dimension.

We do not want to stretch the conclusion too far, however. The results here also point to important shortcomings. The panels fail to deliver a strong univariate value effect, and the momentum effect is too weak. Undoubtedly many other economy-wide and firm-specific features that the model omits contribute to our understanding of these anomalies. Time-varying expected growth-rates, for example, can deliver economically realistic momentum effects (Johnson, 2002). Value effects may be driven by time-varying interest rates and project risk Berk et al., 1999) or financial leverage Ozdagli, 2012; Obreja, 2013).

Nor is our model the only investment-based interpretation of the anomalies. One theory reverses the assumed sign of the market price of investment risks (see Kogan and Papanikolaou, 2012; Papanikolaou, 2012). Thus, good news may (as in our model) increase firm exposure to

25. Factor models explain stock returns via their loadings (betas) with respect to portfolios consisting of long and short positions in stocks sorted according to some characteristic, such as investment rate.

26. The specific parameters are given in the table caption. Because realized investment is infrequent and discrete in the model, the exercise uses the unconditional investment rate of firms as the independent variable.

27. See Chen 2014) for evidence that high market-to-book firms have low effective duration. 
TABLE 7

Investment effects in heterogeneous panels

\begin{tabular}{|c|c|c|c|c|c|c|}
\hline Variable: & 1 & 2 & 3 & 4 & 5 & 6 \\
\hline Profitability & $\begin{array}{c}-0.0004 \\
(1.17) \\
{[1.00]}\end{array}$ & & & $\begin{array}{l}0.0040 \\
(2.15) \\
{[0.45]}\end{array}$ & $\begin{array}{l}0.0039 \\
(2.12) \\
{[0.46]}\end{array}$ & $\begin{array}{l}0.0033 \\
(2.04) \\
{[0.49]}\end{array}$ \\
\hline Investment & & $\begin{array}{c}-0.0034 \\
(2.45) \\
{[0.31]}\end{array}$ & & $\begin{array}{c}-0.0069 \\
(2.36) \\
{[0.36]}\end{array}$ & $\begin{array}{c}-0.0068 \\
(2.36) \\
{[0.36]}\end{array}$ & $\begin{array}{c}-0.0055 \\
(2.27) \\
{[0.44]}\end{array}$ \\
\hline Momentum & & & $\begin{array}{l}0.0011 \\
(1.76) \\
{[0.57]}\end{array}$ & & $\begin{array}{l}0.0003 \\
(1.02) \\
{[0.88]}\end{array}$ & $\begin{array}{l}0.0003 \\
(1.22) \\
{[0.80]}\end{array}$ \\
\hline Beta & & & & & & $\begin{array}{l}0.0010 \\
(1.91) \\
{[0.50]}\end{array}$ \\
\hline
\end{tabular}

Notes: The table shows the results of Fama and MacBeth 1973) regressions of realized excess stock returns on firmspecific characteristics in 500 simulated panels of 2000 firms observed monthly for 50 years. The population consists of equal measure of firms having the baseline parameter values of Section 3.1 and high-investment firms having $\mu=0.16, \delta=0.12, \sigma=0.50, \eta=0.10$. The investment variable is each firm's unconditional rate. The simulation procedure is as described in the caption to Table 5 The coefficients and $t$-statistics in parentheses are the cross-panel means of the Fama-MacBeth estimators. The numbers in brackets are the proportions of panels in which the corresponding $t$-statistic is less than 1.97 .

risky expansion options, but still lower expected returns if investors are willing to pay a premium to gain this exposure 28 Recently, Ai and Kiku 2013 build a general equilibrium model in which option exercise costs are demand-driven and hence procyclical. Thus, their model implies growth options are less risky than assets in place, which also generates a value effect.

\section{CONCLUSION}

Using a neoclassical model with repeated investment and disinvestment, we study how firms' equity risk and expected return behave in response to changes in their operating environment (i.e. productivity) and production technology (i.e. adjustment and operating costs). On the one hand, firms become riskier as profitability declines due to operating leverage when investment is irreversible. On the other hand, firms become riskier as profitability rises due to investment and disinvestment options. The opposing forces of operating leverage and real option effects imply that risk and expected return are sine-like functions of profitability, which is the key asset pricing implication of the model.

For parameters chosen to replicate financial and operating statistics of a sample of U.S. firms, the model's non-monotonic effects are quantitatively important. We illustrate this via two novel predictions. First, return autocorrelation should initially decline and then rise as a function of profitability or market-to-book. Secondly, measures of firm risk should also exhibit the sine-like pattern conditional on profitability. We verify these predictions in the data, providing intriguing new evidence linking real-option effects to variation in return moments.

Both the calibrated model and the return data support the view that firms have moderate operating leverage and non-negligible investment flexibility, and hence that risk increases with profitability for the average firm. This contrasts sharply with a prior literature that has invoked fixed operating costs and investment irreversibility to predict the opposite relation.

28. Kogan and Papanikolaou 2013 show that a version of this model can deliver simultaneous value and profitability effects. 
The lack of support for irreversible investment is not entirely bad news for investment-based asset pricing. In homogeneous panels of simulated baseline-case firms, the model can account for some of the profitability premium and momentum effects in the cross-section, although it makes the value puzzle worse. Interestingly, panels with heterogeneous firms can deliver simultaneous profitability and value effects, and simultaneous profitability and investment effects, that can closely match the patterns in the data. From the latter results, we conclude that investment-based effects may help to explain the coexistence of seemingly contradictory return anomalies.

Future work will need to invoke both within-firm variation in firms' operating environment and cross-firm heterogeneity in technology. Quantifying the plausible cross-sectional distribution of firm parameter values is an important topic for asset pricing research. Our model does not require solving high-dimensional dynamic programmes and yields optimal policies and return moments in closed form. Its tractability makes it well suited as a useful framework for the exploration of more complex populations of heterogeneous firms.

\section{APPENDIX A: PROOFS}

Proof of Lemma W Without the terminating jumps, the $Z$ process is Markovian with time-invariant transition probabilities. Any such process on a bounded interval is stationary. Ergodicity is a consequence of the fact that the process has no terminal states or cycles. Technically, it is Harris-recurrent with each discretely sampled sub-chain being irreducible and aperiodic. See Mevn and Tweedie 1993.

The proposition also asserts that every interval on $(L, U)$ has positive probability under the stationary distribution. This is a consequence of $\sigma_{Z}=-\sigma$ being bounded away from zero on $(L, U)$.

Finally, when the process has terminal jumps $(\eta>0)$, the model assumes that the jumps are independent of the level of $Z$. The stationarity of the distribution during the firm's life then follows immediately, given that its initial position is distributed according to $f_{0}$.

Proof of Proposition $\square$ The text describes the form of the firm's impulse control policy which is standard. When it is in the no-adjustment region the firm value, $J$, satisfies the equilibrium condition

$$
\mathrm{E}[d J / J]+\Pi / J-r=-\operatorname{Cov}[d J / J, d \Lambda / \Lambda] .
$$

The jump version of Itô's lemma says that $J=J(\theta, K)$ obeys:

$$
d J=\left[J_{\theta} \theta \mu-J_{K} \delta K+\frac{1}{2} J_{\theta \theta} \theta^{2} \sigma^{2}\right] d t+J_{\theta} \theta \sigma d W^{\theta}-J d N^{\Lambda}-J d N^{I} .
$$

Hence

And $\mathrm{E}[d J]$ is all the $d t$ terms, plus

$$
\operatorname{Cov}[d J, d \Lambda / \Lambda]=\rho J_{\theta} \theta \sigma \sigma_{\Lambda}-J \psi \eta_{\Lambda}
$$

$$
-J \eta_{\Lambda}-J \eta_{I}
$$

The whole partial differential equation (PDE) then is

$$
\left[\frac{1}{2} J_{\theta \theta} \theta^{2} \sigma^{2}+J_{\theta} \theta \mu-J_{K} \delta K\right]-J\left(\eta_{\Lambda}+\eta_{I}\right)-r J+\left[\theta^{1-\gamma} K^{\gamma}-m K\right]+\left[\rho J_{\theta} \theta \sigma \sigma_{\Lambda}\right]-J \psi \eta_{\Lambda}=0 .
$$

To verify homogeneity, we guess the solution form $J=\theta V(K / \theta)$ and use

$$
\begin{aligned}
J_{K} & =V^{\prime} \\
J_{\theta} & =V-(K / \theta) V^{\prime} \\
J_{\theta \theta} & =-\left(K / \theta^{2}\right) V^{\prime}+\left(K / \theta^{2}\right) V^{\prime}+\left(K^{2} \theta^{3}\right) V^{\prime \prime}=\left(K^{2} \theta^{3}\right) V^{\prime \prime} .
\end{aligned}
$$

The PDE then becomes an ordinary differential equation (ODE) in $V(Z)$ with $Z=K / \theta$. Grouping terms and dividing by $\theta$ :

where we have defined

$$
\frac{1}{2} Z^{2} \sigma^{2} V^{\prime \prime}-\left[\mu^{R N}+\delta\right] Z V^{\prime}-\left[\hat{r}-\mu^{R N}\right] V+\left[Z^{\gamma}-\hat{m} Z\right]=0 .
$$

$$
\begin{aligned}
\hat{r} & =r+\eta^{R N} \\
\eta^{R N} & =\eta_{I}+(1+\psi) \eta_{\Lambda} \\
\hat{m} & =m-P_{U} \eta^{R N} \\
\mu^{R N} & =\mu+\rho \sigma \sigma_{\Lambda}
\end{aligned}
$$


The form of the solution to equation A.2 is well known: it is the sum of the general solution to the homogenous version (without the $\Pi$ terms) and a particular solution having the same form as the $\Pi$ terms. This yields

$$
V(Z)=A Z^{\gamma}-S Z+D_{N} Z^{\lambda_{N}}+D_{P} Z^{\lambda_{P}}
$$

where

and

$$
\begin{gathered}
A=\frac{1}{\hat{r}+\gamma \delta+(\gamma-1) \mu^{R N}-\frac{1}{2} \gamma(\gamma-1) \sigma^{2}} \\
S=\frac{m}{(\hat{r}+\delta)}
\end{gathered}
$$

$$
\lambda_{P, N}=\frac{b \pm \sqrt{b^{2}+2\left(\hat{r}-\mu^{R N}\right) \sigma^{2}}}{\sigma^{2}}
$$

and $b=\left(\mu^{R N}+\delta+\frac{1}{2} \sigma^{2}\right)$. It is straightforward to show that the regularity condition (R) imposed in the proposition is sufficient to guarantee both that the denominator in $A$ is positive and that $\lambda_{P, N}$ are real. In fact, for later note that $\lambda_{N}<0$ and $\lambda_{P}>1$.

The boundary conditions are derived from the optimality conditions of the policy problem. As described in the text, the firm will choose an investment threshhold $\theta_{L}(K)$ and a post-investment level of capital, $K^{\prime}\left(\theta_{L}\right)$. A necessary condition for optimality of these functions is the value matching condition (VMC):

$$
J\left(K^{\prime}, \theta_{L}(K)\right)=J\left(K, \theta_{L}(K)\right)+F_{L} \theta_{L}^{1-\gamma} K^{\gamma}+P_{L}\left(K^{\prime}-K\right) .
$$

This states that the post-investment value of the firm is the pre-investment value plus the funds injected less costs. Under the conjectured solution of the firm's problem, this condition becomes

$$
V\left(\frac{K^{\prime}\left(\theta_{L}\right)}{\theta_{L}(K)}\right)=V\left(\frac{K}{\theta_{L}(K)}\right)+F_{L}\left(\frac{K}{\theta_{L}(K)}\right)^{\gamma}+P_{L}\left(\frac{K^{\prime}\left(\theta_{L}\right)}{\theta_{L}(K)}-\frac{K}{\theta_{L}(K)}\right) .
$$

In terms of the re-scaled variable $Z$, the condition requires finding points $G, L$ to satisfy

$$
V(G)=V(L)+F_{L} L^{\gamma}+P_{L}(G-L) .
$$

Doing so identifies the optimal investment policy $\theta_{L}(K)=K / L$ and $K^{\prime}=G \theta_{L}=(G / L) K$.

Likewise the equivalent VMC for disinvestment in re-scaled form is:

$$
V(H)=V(U)+F_{U} U^{\gamma}+P_{U}(H-U) .
$$

Finding such points $U, H$ defines the policy $\theta_{U}(K)=K / U$ and $K^{\prime \prime}=H \theta_{U}=(H / U) K$. (Note that $H-U<0$.)

Given these VMCs, functionally differentiating with respect to the barrier positions, yield the smooth pasting conditions (SPCs) as additional necessary conditions of optimality. These are:

$$
\begin{aligned}
V^{\prime}(L) & =-\gamma F_{L} L^{\gamma-1}+P_{L}, \\
V^{\prime}(G) & =P_{L}, \\
V^{\prime}(U) & =-\gamma F_{U} U^{\gamma-1}+P_{U}, \\
V^{\prime}(H) & =P_{U} .
\end{aligned}
$$

A solution to the ODE in equation A.2 together with a set of constants $G, L, U, H$, satisfying the above conditions constitutes a solution to the original PDE and (unscaled) necessary conditions, and therefore verifies homogeneity.

When equation A.3 is plugged into each of the SPCs and VMCs, the result is a system of six equations in $G, L, U$, $H, D_{N}$, and $D_{P}$. The system is linear in the last two, given the first four.

$$
\begin{aligned}
D_{N}= & \frac{1}{\Delta}\left[\left(H^{\lambda P}-U^{\lambda P}\right)\left(A\left(G^{\gamma}-L^{\gamma}\right)-S(G-L)-F_{L} L^{\gamma}-P_{L}(G-L)\right)\right. \\
& \left.-\left(G^{\lambda P}-L^{\lambda_{P}}\right)\left(A\left(H^{\gamma}-U^{\gamma}\right)-S(H-U)-F_{U} U^{\gamma}-P_{U}(H-U)\right)\right]
\end{aligned}
$$

and

$$
\begin{aligned}
D_{P}= & \frac{1}{\Delta}\left[\left(G^{\lambda_{N}}-L^{\lambda_{N}}\right)\left(A\left(H^{\gamma}-U^{\gamma}\right)-S(H-U)-F_{U} U^{\gamma}-P_{U}(H-U)\right)\right. \\
& \left.-\left(H^{\lambda_{N}}-U^{\lambda_{N}}\right)\left(A\left(G^{\gamma}-L^{\gamma}\right)-S(G-L)-F_{L} L^{\gamma}-P_{L}(G-L)\right)\right]
\end{aligned}
$$

where

$$
\Delta=\left(G^{\lambda_{P}}-L^{\lambda_{P}}\right)\left(H^{\lambda_{N}}-U^{\lambda_{N}}\right)-\left(G^{\lambda_{N}}-L^{\lambda_{N}}\right)\left(H^{\lambda_{P}}-U^{\lambda_{P}}\right) .
$$

These constants multiply the perpetual option components of the firm value function. Positivity follows from the fact that these components, as solutions to an optimization problem, must add value to the firm. Formally, from the above 
expressions, one can verify that $\lim _{L \rightarrow 0} D_{N}=0$ and $\lim _{U \rightarrow \infty} D_{P}=0$. That is, the firm is free to not exercise its options, in which case they contribute zero value. Any positive exercise probability implies non-negative value.

The value function is monotonic in $\theta$ because $\frac{d \Pi}{d \theta}>0$ and the distribution function of future values of $\theta_{s}$ (under the risk-neutral measure) is strictly increasing in $\theta_{t}$ for $s>t$. So for any investment policy, the discounted expected sum of profits is strictly increasing. And note that $J_{\theta}=V-Z V^{\prime}>0$ is equivalent to Property (A): $\left(1-Z V^{\prime} / V\right)>0$ assuming $V>0$.

Monotonicity of the value function with respect to $K$ cannot be guaranteed in general since capital disposal is costly. However, $P_{U} \geq 0$ and $F_{U}=0$ is clearly sufficient since then any investment policy requiring $K^{\prime}$ in capital can always be implemented with $K^{\prime \prime}>K^{\prime}$ by paying out the difference and receiving positive value. In general, for any $P_{U} \geq 0$, there will be some level of $F_{U}$ below which monotonicity must hold. And note that Property (B) $J_{K}>0$ is equivalent to $V^{\prime}>0$.

As discussed in the text, another facet of the problem is the abandonment option. If the solution found by the above procedure does not yield an everywhere positive firm value (which can happen, e.g. if $P_{U}$ is very negative), then it is not consistent with limited liability, i.e. the conclusions above are subject to condition (P). In that case, the system must be re-solved with the boundary conditions $V(U)=0$ and $V^{\prime}(U)=0$ replacing equations A.6 and A.9.

Proof of Proposition 2 By the definition of the pricing kernel, the firm's expected excess return is minus the covariance of $d J / J$ with $d \Lambda / \Lambda$. This quantity was derived above as

$$
\rho\left(J_{\theta} / J\right) \theta \sigma \sigma_{\Lambda}-\psi \eta^{\Lambda} .
$$

This is equivalent to the expression in the text using $J_{\theta}=V-(K / \theta) V^{\prime}$. Properties (A) and (B) above are equivalent to $0<\left(1-Z V^{\prime} / V\right)<1$. Multiplying by $\pi_{\theta}$ yields the bounds in the proposition.

Proof of Proposition 3 Using equations A.3 A.12, the expected excess return can be written

$$
\begin{aligned}
\operatorname{EER}(Z) & =\pi_{\theta} \frac{A Z^{\gamma}(1-\gamma)+D_{N} Z^{\lambda_{N}}\left(1-\lambda_{N}\right)+D_{P} Z^{\lambda_{P}}\left(1-\lambda_{P}\right)}{V(Z)} \\
& =\pi_{\theta} \frac{\widehat{V(Z)}}{V(Z)} \frac{A Z^{\gamma}(1-\gamma)+D_{N} Z^{\lambda_{N}}\left(1-\lambda_{N}\right)+D_{P} Z^{\lambda_{P}}\left(1-\lambda_{P}\right)}{\widehat{V(Z)}}
\end{aligned}
$$

where we define $\widehat{V(Z)} \equiv V(Z)+S Z=A Z^{\gamma}+D_{N} Z^{\lambda_{N}}+D_{P} Z^{\lambda P}$, which is the value of the firm excluding the liability due to fixed costs. Thus, we hav 29

$$
\operatorname{EER}(Z)=\pi_{\theta} \frac{\widehat{V(Z)}}{V(Z)}\left[(1-\gamma) w_{A}(Z)+\left(1-\lambda_{N}\right) w_{G}(Z)+\left(1-\lambda_{P}\right) w_{C}(Z)\right] .
$$

where $w_{A}+w_{C}+w_{G}=1$. The three additive terms in this expression are what the proposition labels $E E R_{A I P}(Z), E E R_{E O}(Z)$, and $E E R_{C O}(Z)$. The term $\frac{\widehat{V(Z)}}{V(Z)}=\left(1+\frac{S Z}{V(Z)}\right)>1$ represents the risk amplification of operating leverage.

The risk contribution of assets in place is given by $(1-\gamma) w_{A}(Z)(\widehat{V(Z)} / V(Z))$. Clearly $w_{A}$ is positive and increasing in $Z$. The operating leverage term is as well since the derivative of $1+S Z / V$ has the same sign as that of $Z / V$, which is $\left(V-Z V^{\prime}\right) / V^{2}>0$ by property (A). It follows that the total risk premium contribution of assets in place is increasing in $Z$ as claimed.

By the same reasoning, the contraction option's contribution to the risk premium, $\left(1-\lambda_{P}\right) w_{C}(Z)(\widehat{V(Z)} / V(Z))$, is negative and decreasing since $\lambda_{P}>1$ and $w_{C}(Z)$ is increasing.

The remaining claim is that the growth option term is positive and decreasing in $Z$. This term is equal to ( $1-$ $\left.\lambda_{N}\right) D_{N} Z^{\lambda_{N}} / V$, which is positve because $\left(1-\lambda_{N}\right)>0$ and $D_{N}>0$. The sign of the derivative is thus the sign of $\lambda_{N} V-Z V^{\prime}$. Since $V>0$ by limited liability, and $\lambda_{N}<0$, a sufficient condition for a negative derivative is simply $V^{\prime}>0$. But this is implied by condition (B).

This concludes the proof of the proposition.

\section{APPENDIX B: INCLUDING DEBT}

This appendix describes two tractable ways of embedding the firm's problem in an economy with debt while preserving the qualitative features of risk and expected return described in the main body of the article.

We assume that debt is in the form of a credit line whose instantaneous interest rate $i$ is set to make the debt worth its face value, $B$, as long as the firm is alive. Adjusting the level of borrowing will be assumed costless (as is adjusting equity).

29. We thank Ali Ozdagli for suggesting this decomposition. 
So the firm will adjust debt continually as a function of the state variable $Z$. We formulate the debt choice as a simplified trade-off model where the firm gets tax benefits proportional to the amount of debt and also incurs convex monitoring costs. We can view these costs as a reduced form for the expense of setting up the bank relationship, overcoming contracting problems, and achieving first-best. As a consequence of the monitoring, then, investment (and potential abandonment decisions) are taken to maximize firm—not equity—value (i.e. $J$ not $J-B$ ). Formally, the firm now solves the Bellman equation

$$
\max _{B, U, H, G, L}(\mathcal{D} J+\Phi(B, J))=0
$$

where $\mathcal{D} J$ stands for the left-hand side of equation A.1 and $\Phi(B, J)$ is the net benefit flow term. Optimal debt can then be characterized by the first-order condition (FOC) for $B$ holding $J$ fixed: $\partial \Phi / \partial B=0$. This is analogous to the characterization of optimal consumption in the Merton problem.

Our first formulation simply says that the tax benefit per unit time is $\tau i B$ and the monitoring costs are quadratic in $B / J, e . g \cdot \frac{1}{2} c(B / J)^{2} J=\frac{1}{2} c(B / J) B$. Thus, $\Phi(B, J)=\tau i B-\frac{1}{2} c(B / J) B$, which implies monitoring costs increase both with absolute level of debt and with market leverage. The FOC then yields the optimal policy

$$
B^{*}=(\tau i / c) J
$$

With this policy, the net benefit flow to the firm per unit time is $\frac{1}{2} \frac{\tau^{2} i^{2}}{c} J_{t}$, which depends on the interest rate on the debt. If debt is going to be risky, this interest rate will be a function of firm value. So this net flow term then adds a very ugly non-linear component to the ODE. A natural way around this is to just make the tax shield a function of $r$ instead of $i$. That is, one can posit that the tax rules limit the deductibility of interest to $r B$, not $i B$. This shuts down the rather complicated (and not relevant) mechanism whereby the firm has an incentive to increase the riskiness of debt just to increase tax shields. With this assumption, the simple model yields

$$
B^{*}=\frac{\tau r}{c} J \equiv b^{*} J
$$

with net benefit flow $\frac{1}{2} \frac{\tau^{2} r^{2}}{c} J_{t}$. This formulation says that book leverage $B / K$ is proportional to $J / K$, the market-to-book ratio of the whole firm. Or, since the main determinant of this ratio is profitability, it says that more profitable firms borrow more. Note that $B$ proportional to $J$ is a statement about the quantity of debt; the unit value of debt is always one (until default, to be discussed below). Also note that, if the coefficient $b^{*}$ is less than one, the model keeps the equity value, $J-B$, positive.

This is an appealing formulation, which essentially achieves our objective. Since equity value is just a multiple of firm value, the graph of the equity risk premium is identical to the graph of the firm risk premium. As operating leverage increases (with $Z=K / \theta$ rising) the decline in debt exactly offsets the financial leverage. So debt has no net effect on equity risk.

This is not to say debt has no effect on the problem. The PDE that characterizes firm value, $J$, has to be modified because the firm profit term $\Pi$ incorporates the net tax benefit flow. For the above model, the term now looks like

$$
\theta^{1-\gamma} K^{\gamma}-m K+\hat{\tau} J
$$

where $\hat{\tau} \equiv \frac{1}{2} \tau r b^{*}$. Following the same derivation as given above, when the PDE is turned into an ODE for $V$, the only modification is that the adjusted interest rate becomes

$$
\hat{r}=r+\eta^{R N}-\hat{\tau}
$$

The equation is solved as before, with the same boundary conditions.

Once we obtain the solution $J$, then, since debt is worth its face value, $J_{D}=B$, equity is just $J_{E}=J-B$. To compute the equity risk premium, the full expression for $-\operatorname{Cov}\left[d J_{E} / J_{E}, d \Lambda / \Lambda\right]$ is

$$
-\rho \sigma \sigma_{\Lambda}\left[\frac{\theta}{J_{E}} \frac{\partial J_{E}}{\partial \theta}\right]+\left(\psi \eta^{\Lambda}\right)
$$

The first term pertains to diffusive $\theta$ risk. For our very simple model, $J_{E}=\left(1-b^{*}\right) J$. So this is the same as the firm's diffusive risk premium:

$$
1-Z \frac{V^{\prime}}{V}
$$

The second term is the compensation for systematic jump risk.

Now consider a second debt formulation in which market leverage will not be constant. We instead introduce the assumption that upon default the capital stock has non-zero liquidation value given by $P_{0} K$. Leverage will now vary with the firm's liquidation value. This captures the role of tangible assets in determining a firm's debt capacity. Formally, we induce this dependence by specifying that the monitoring cost looks like

$$
\frac{1}{2} c\left(\frac{B}{J}-\left[\frac{P_{0} K}{J}-1\right]\right)^{2} J .
$$


The FOC then yields

$$
B^{*}=\left(\frac{\tau r}{c}-1\right) J+P_{0} K=\left(b^{*}-1\right) J+P_{0} K
$$

Assuming $b^{*}<1$, this model has book leverage declining in profitability, as measured by $Q=J / K$. Loss-making firms increase their borrowing, whereas investing firms may hold net cash $(B<0)$. Equity value is

$$
J_{E}=\left(2-b^{*}\right) J-P_{U} K \quad \text { or } \quad V_{E}=\left(2-b^{*}\right) V-P_{U} Z,
$$

which remains positive for $b^{*}<1$ because $J \geq P_{0} K$.

This model is still easy to solve: the net benefit flow contributes one term that is linear in $J$ and one that is linear in $K$. These just lead to slightly different adjustments to the ODE inputs $\hat{r}$ and $\hat{m}$. Specifically, we find

$$
\begin{aligned}
& \hat{r}=r+\eta^{R N}-r \tau\left(\frac{1}{2} b^{*}-1\right) \\
& \hat{m}=m-\eta^{R N} P_{0}-r \tau P_{0} .
\end{aligned}
$$

This formulation of debt tends to steepen the graph of risk or expected return as a function of productivity (or log book-to-market or profitability). Numerical results (available from the authors upon request) indicate that the primary within-firm implication identified in the text is preserved: risk and expected return are sine-like functions of productivity.

\section{APPENDIX C: CALIBRATION AND SAMPLE DETAILS}

This appendix gives the details of the calibration methodology described in Section 3.1 It also describes the data sample used in Sections 3.1 and 3.2

A first set of parameters in Table 1 are taken from the literature. These include the real interest rate and the volatility of the pricing kernel. The former is per, for example, Table 1 in Campbel1 2003). The latter is taken from the calibration of Berk et al. 1999), who use a monthly volatility of 0.40. Our value is also equal to the (unconditional) level implied by the general equilibrium calibration of Bansal, Kiku, and Yaron 2012) (the calculation of which is available upon request).

Also from the literature, we fix the production function's returns-to-scale parameter. Hennessy and Whited 2007 provide an estimate for this parameter of $0.627 \pm 0.219$. Our parameter is compatible with this range. Several asset pricing papers take higher values: Cooper 2006 and Kogan and Papanikolaou 2014) both use 0.85. Many works, including Carlson et al. 2004 and Gomes et al. 2003) use no curvature, which is equivalent to $\gamma=1.0$.

Next, we fix some parameters based on clear identification from the moments of our data sample. The sample average of depreciation over assets $(0.0437)$ is taken to be the parameter $\delta$. Given $\gamma$ as fixed above, the volatility of firm sales in the model is $(1-\gamma) \sigma$. We use this to fix $\sigma$ given the volatility of sales growth $(0.1345)$ in our sample. We note that $(1-\gamma) \sigma$ is also the volatility of TFP innovations in the model. Recently, Imrohoroglu and Tüze 2014 estimate firm-level TFP volatility to be 0.27 in annual data. Hennessy and Whited 2007) use an estimated value of 0.1185 per year. Our value is between these, but closer to the latter.

Next, we directly identify the $(\log )$ growth rate of the model's state variable $Z$ via the average growth rate of $\log$ sales over assets, which in our sample is 0.00054 . In the model, sales over assets corresponds to $Z^{1 / 1-\gamma}$. And the growth rate of the $\log$ of this quantity is $\left(\mu+\delta-\frac{\sigma^{2}}{2}\right) /(\gamma-1)$. Given the values for $\gamma, \delta$, and $\sigma$, this fixes the value for $\mu$.

Given the value for $\sigma_{\Lambda}$, the Sharpe ratio of any firm is $\rho \sigma_{\Lambda}$. This identifies correlation of pricing kernel with productivity $(\rho)$ using the mean Sharpe ratio of returns (0.2298) in the sample. Next, the Sharpe ratio of the market portfolio in the model is related to that of a firm by the factor $\left[\rho^{2}+\left(\rho^{(m)}\right)^{2}\right]^{-1 / 2}$ when the market portfolio is taken to be a large number of equally weighted stocks. In the data, the ratio of the market Sharpe to the average firm Sharpe (or, equivalently, the ratio of the average firm volatility to the market volatility) is 1.6780 which pins down $\rho^{(m)}$.

The calibration also fixes the firm termination intensity $\eta^{I}$, which affects firms' effective interest rate. The value 0.03 gives an expected firm life of 33 years. This closely matches the mean age since foundation of 35.2 in the comprehensive Field-Ritter data set as of 14 April 2014 (see http://bear.warrington.ufl.edu/ritter/FoundingDates.htm accessed 10 June 2015).

The remaining parameters are fit by the method of simulated moments. To do this, we target the following seven operating statistics: the mean and standard deviation of the log book-to-market ratio; the mean return on firm equity; the mean profitability over assets; the mean rates of investment and disinvestment scaled by assets; the mean quasi-fixed costs. The moment criterion function weighs each moment squared error in inverse proportion to its sampling error, which is calculated from standard errors clustered at the firm and year level.

Our data sample spans all firms for which we can obtain the relevant items in COMPUSTAT and CRSP. We omit firms with negative book values and require that no monthly return observation is missing. Following standard practice in the empirical asset pricing literature, we exclude banks ( $\mathrm{FF}=44)$, insurance companies $(\mathrm{FF}=45)$, trading firms $(\mathrm{FF}=47)$, and utilities $(\mathrm{FF}=31)$. Our sample covers the 1960-2009 period. As financial statistics, we compute for each firm-month 
HACKBARTH \& JOHNSON REAL OPTIONS AND RISK DYNAMICS

observation the log value of the book-to-market ratio, the annual stock return in excess over the risk-free rate, the annual stock return volatility, and the firm's and the market's Sharpe ratio. The book-to-market ratio is book equity scaled by market value of equity, and the Sharpe ratio equals annual excess return over annual stock return volatility.

In addition, we construct the following operating statistics. Investment is measured using capital expenditures (capx) scaled by assets (at). Disinvestment is measured by using sale of property, plant, and equipment (sppe) scaled by assets. To remove frequent but small disinvestments, we require that sales of property, plant, and equipment exceed $0.5 \%$ of assets. Profitability is measured as return on assets, which equals operating income before depreciation (oibdp) divided by assets. Depreciation (dp) and selling, general, and administrative expenses (xsga) are also scaled by assets. Quasi-fixed costs are the intercept from a regression of log of costs over assets on log sales over assets, where costs are the sum of costs of good sold, cogs, and, if available, selling, general, and administrative expenses, xsqaq. Finally, sales growth volatility is the standard deviation of the change in the log of sales over assets.

Finally, we compute firm-level autocorrelation coefficients of investment and profitability and firm-level correlation coefficients of investment and stock return and investment and $Q$. $Q$ equals market value of equity plus book value of debt (dltt) plus book value of preferred equity (pstkrv) minus inventories (invt) and deferred taxes (txdb) scaled by assets.

Acknowledgments. We are very grateful to Dimitri Vayanos (the editor) and three anonymous referees for extremely constructive advice. We thank Jonathan Berk, Jason Chen, Bob Chirinko, Lorenzo Garlappi, Graeme Guthrie, Ali Ozdagli, Dimitris Papanikolaou, Tano Santos, Jianfeng Yu, and Lu Zhang for their thoughtful comments. We also thank conference participants at the 2011 NBER Asset Pricing Meeting at Stanford Unversity; the 2012 Utah Winter Finance Conference; the 2012 WFA Meeting; and seminar audiences at the Texas A\&M University; the University of Calgary; the University of Georgia; the University of Illinois, Chicago; the University of Illinois, Urbana-Champaign; and the University of Rochester. Lifeng Gu and Nuri Ersahin provided excellent research assistance.

\section{REFERENCES}

ABEL, A. B., DIXIT, A., EBERLY, J. C. and PINDYCK, R. S. (1996), “Options, the Value of Capital, and Investment", The Quarterly ournal of Economics, 111, 753-777.

ABEL, A. B. and EBERLY, J. C. (1996), "Optimal Investment with Costly Reversibility", Review of Economic Studies, 63, 581-993.

AI, H. and KIKU, D. (2013), "Growth to Value: Option Exercise and the Cross Section of Equity Returns", Journal of Financial Economics, 107, 325-349.

BANSAL, R., KIKU, D. and YARON, A. (2012), "An Empirical Evaluation of the Long-run Risks Model for Asset Prices", Critical Finance Review, 1, 183-221.

BERK, J. B. (1995), “A Critique of Size-related Anomalies”, Review of Financial Studies, 8, 275-286.

BERK, J. B., GREEN, R. C. and NAIK, V. (1999), "Optimal Investment, Growth Options, and Security Returns", Journal of Finance, 54, 1553-1607.

BERTOLA, G. (1998), "Irreversible Investment", Research in Economics, 52, 3-37.

BLOOM, N. (2009), "The Impact of Uncertainty Shocks", Econometrica, 77, 623-685.

CAMPBELL, J. Y. (2003), "Consumption-based Asset Pricing”, Handbook of the Economics of Finance, 1, $803-887$.

CARLSON, M., FISHER, A. and GIAMMARINO, R. (2004), "Corporate Investment and Asset Price Dynamics: Implications for the Cross-section of Returns" Journal of Finance, 59, 2577-2603.

CHEN, H. J. (2014), “Do Cash Flows of Growth Stocks Really Grow Faster?” College Station: Texas A\&M University (Working Paper).

COOPER, I. (2006), "Asset Pricing Implications of Nonconvex Adjustment Costs and Irreversibility of Investment", Journal of Finance, 61, 139-170.

COOPER, M. J., GULEN, H. and SCHILL, M. J. (2008), “Asset Growth and the Cross-section of Stock Returns”, Journal of Finance, 63, 1609-1651.

EISFELDT, A. L. and RAMPINI, A. A. (2006), "Capital Reallocation and Liquidity", Journal of Monetary Economics, 53, 369-399.

FAMA, E. F. and FRENCH, K. R. (2006), "Profitability, Investment and Average Returns", Journal of Financial Economics, 82, 491-518.

FAMA, E. F. and FRENCH, K. R. (2015), “A Five-factor Asset Pricing Model”, Journal of Financial Economics, 16, $1-22$.

FAMA, E. F. and MacBETH, J. D. (1973), “Risk, Return, and Equilibrium: Empirical Tests”, Journal of Political Economy, 21, 607-636.

GARLAPPI, L., SHU, T. and YAN, H. (2008), "Default Risk, Shareholder Advantage and Stock Returns", Review of Financial Studies, 81, 2743-2778.

GARLAPPI, L. and YAN, H. (2011), "Financial Distress and the Cross Section of Equity Returns", Journal of Finance, 66, 789-822.

GOMES, J., KOGAN, L. and ZHANG, L. (2003), “Equilibrium Cross Section of Returns”, Journal of Political Economy, 111, 693-732. 
GUTHRIE, G. (2011), “A Note on Operating Leverage and Expected Rates of Return”, Finance Research Letters, 8, 88-100.

HENNESSY, C. A. and WHITED, T. M. (2007), "How Costly is External Financing? Evidence from a Structural Estimation", The Journal of Finance, 62, 1705-1745.

IMROHOROĞLU, A. and TÜZEL, S. (2014), "Firm-Level Productivity, Risk, and Return", Management Science, 60, 2073-2090.

JOHNSON, T. C. (2002), "Rational Momentum Effects", Journal of Finance, 57, 585-608.

KOGAN, L. and PAPANIKOLAOU, D. (2012), "Economic Activity of Firms and Asset Prices", Annual Review of Financial Economics, 4, 361-384.

KOGAN, L. and PAPANIKOLAOU, D. (2013), "Firm Characteristics and Stock Returns: The Role of Investment-specific Shocks", Review of Financial Studies, 26, 2718-2759.

KOGAN, L. and PAPANIKOLAOU, D. (2014), "Growth Opportunities, Technology Shocks and Asset Prices", Journal of Finance, 69, 675-718.

LI, E., DIMITRY LIVDAN, X. N. and ZHANG, L. (2009), “Anomalies”, Review of Financial Studies, 22, $4301-4334$.

MEYN, S. P. and TWEEDIE, R. L. (1993), "Stability of Markovian Processes II: Continuous-time Processes and Sampled Chains", Advances in Applied Probability, 25, 487-517.

NOVY-MARX, R. (2013), “The Other Side of Value: The Gross Profitability Premium”, Journal of Financial Economics, 108, 1-28.

NYBERG, P. and PÖYRY, S. (2013), "Firm Expansion and Stock Price Momentum", Review of Finance, 15, 1-41.

OBREJA, I. (2013), "Book-to-market Equity, Financial Leverage and the Cross-Section of Stock Returns", Review of Financial Studies, 26, 1146-1189.

OZDAGLI, A. K. (2012), "Financial Leverage, Corporate Investment, and Stock Returns", Review of Financial Studies, 25, 1033-1069.

PAPANIKOLAOU, D. (2012), "Investment Shocks and Asset Prices", Journal of Political Economy, 119, 639-685.

PINDYCK, R. S. (1988), "Irreversible Investment, Capacity Choice, and the Value of the Firm", American Economic Review, 78, 969-85.

RAMEY, V. A. and SHAPIRO, M. D. (2001), "Displaced Capital: A Study of Aerospace Plant Closings", Journal of Political Economy, 109, 958-992.

SAGI, J. S. and SEASHOLES, M. S. (2007), Firm-Specific Attributes and the Cross-Section of Momentum", Journal of Financial Economics, 84, 389-434.

TITMAN, S., WEI, K.-C. and XIE, F. (2004), "Capital Investments and Stock Returns", Journal of Financial and Quantitative Analysis, 39, 677-700.

ZHANG, L. (2005), “The Value Premium”, Journal of Finance, 60, 67-103. 